Linköping Studies in Science and Technology

Dissertation No. 1965

\title{
Transport Analytics Based on Cellular Network Signalling Data
}

\author{
David Gundlegård
}

Norrköping 2018 
Transport Analytics Based on Cellular Network Signalling Data David Gundlegård

Linköping Studies in Science and Technology. Dissertation No. 1965 Copyright (C) 2018 David Gundlegård, unless othwerwise noted ISBN 978-91-7685-172-2

ISSN 0345-7524

Printed by LiU-Tryck, Linköping 2018 


\section{Abstract}

Cellular networks of today generate a massive amount of signalling data. A large part of this signalling is generated to handle the mobility of subscribers and contains location information that can be used to fundamentally change our understanding of mobility patterns. However, the location data available from standard interfaces in cellular networks is very sparse and an important research question is how this data can be processed in order to efficiently use it for traffic state estimation and traffic planning.

In this thesis, the potentials and limitations of using this signalling data in the context of estimating the road network traffic state and understanding mobility patterns is analyzed. The thesis describes in detail the location data that is available from signalling messages in GSM, GPRS and UMTS networks, both when terminals are in idle mode and when engaged in a telephone call or a data session. The potential is evaluated empirically using signalling data and measurements generated by standard cellular phones. The data used for analysis of location estimation and route classification accuracy (Paper I-IV in the thesis) is collected using dedicated hardware and software for cellular network analysis as well as tailor-made Android applications. For evaluation of more advanced methods for travel time estimation, data from GPS devices located in Taxis is used in combination with data from fixed radar sensors observing point speed and flow on the road network (Paper V). To evaluate the potential in using cellular network signalling data for analysis of mobility patterns and transport planning, real data provided by a cellular network operator is used (Paper VI).

The signalling data available in all three types of networks is useful to estimate several types of traffic data that can be used for traffic state estimation as well as traffic planning. However, the resolution in time and space largely depends on which type of data that is extracted from the network, which type of network that is used and how it is processed. 
The thesis proposes new methods based on integrated filtering and classification as well as data assimilation and fusion that allows measurement reports from the cellular network to be used for efficient route classification and estimation of travel times. The thesis also shows that participatory sensing based on GPS equipped smartphones is useful in estimating radio maps for fingerprint-based positioning as well as estimating mobility models for use in filtering of course trajectory data from cellular networks.

For travel time estimation, it is shown that the CEP-67 location accuracy based on the proposed methods can be improved from 111 meters to 38 meters compared to standard fingerprinting methods. For route classification, it is shown that the problem can be solved efficiently for highway environments using basic classification methods. For urban environments the link precision and recall is improved from 0.5 and 0.7 for standard fingerprinting to 0.83 and 0.92 for the proposed method based on particle filtering with integrity monitoring and Hidden Markov Models.

Furthermore, a processing pipeline for data driven network assignment is proposed for billing data to be used when inferring mobility patterns used for traffic planning in terms of OD matrices, route choice and coarse travel times. The results of the largescale data set highlight the importance of the underlying processing pipeline for this type of analysis. However, they also show very good potential in using large data sets for identifying needs of infrastructure investment by filtering out relevant data over large time periods. 


\section{Populärvetenskaplig Sammanfattning}

Dagens mobila nätverk genererar stora mängder signaleringsdata. En stor del av denna data används för att hålla reda på var i nätet mobiltelefoner befinner sig för att de ska kunna upprätthålla pågående samtal eller vara nåbara för nya samtal. Från denna typ av data är det alltså möjligt att lokalisera var en stor mängd mobiltelefoner befinner sig över tid, vilket möjliggör en helt ny förståelse för mänsklig mobilitet. Den lokalisering som kan åstadkommas med denna data är oftast väldigt grov och en viktig frågeställning i detta arbete är att avgöra hur denna data ska behandlas för att möjliggöra en bättre förståelse av mobilitetsmönster och nyttjandet av olika transportsystem.

Avhandlingen syftar till att analysera vilken potential och vilka begränsningar som finns med att utnyttja signaleringsdata från mobilnäten för att skatta tillståndet i transportsystemet, samt att förstå olika typer av mobilitetsmönster. Avhandlingen beskriver i detalj vilken signaleringsdata som är tillgänglig i olika mobila nätverk, både när telefonen är påslagen men inte används och när den används för samtal eller nedladdning av data.

Potentialen med systemet har studerats empiriskt med data från mobiltelefoner. Speciell hård- och mjukvara har använts i syfte att förstå den data som genereras mellan mobiltelefonen och nätverket. I syfte att skatta den rumsliga upplösningen för signaleringsdata har specialanpassade Android-applikationer som kombinerar signaleringsdata med data från GPS-mottagaren utvecklats och använts. För att analysera mer avancerade metoder där man kombinerar olika datatyper för skattning av tillståndet på vägnätet har även data från GPS-utrustade taxibilar samt fast monterade radarsensorer använts. När det gäller skattning av mobilitetsmönster över större geogra- 
fiska områden för stads- och trafikplanering har data från en operatörs nätverk använts.

Resultatet visar tydligt att de signaleringsdata som är tillgängliga i de mobila nätverken är användbar för att skatta flera typer av trafikdata, exempelvis restider, ruttval eller reseefterfrågan mellan olika zoner. Däremot är det också tydligt att beroende på vilken typ av information som extraheras samt hur denna data bearbetas kommer att påverka resultatet signifikant.

I arbetet föreslås nya metoder baserade på integrerad filtrering och klassificering samt metoder för att kombinera olika datatyper och modellutdata för att möjliggöra effektiv bearbetning av högupplöst signaleringsdata i syfte att skatta restider och vägval i vägnätet. Vidare beskrivs en ny process för att hantera mer lågupplöst data $\mathrm{i}$ syfte att förstå mobilitetsmönster användbara för stads- och trafikplanering. Slutligen beskrivs också hur användningen av smarta telefoner och specialutvecklade Androidapplikationer kan utnyttjas till att förbättra prestanda i hanteringen av signaleringsdata i mobilnätet, exempelvis genom bättre skattning av restid och vägval i vägnätet. 


\section{Acknowledgements}

First of all, I would like to thank my main supervisor Prof. Johan M Karlsson and my co-supervisor Prof. Di Yuan for all their patient support, encouragement and guidance throughout the years.

I am also very thankful to all the colleagues at the division of Communication and Transport Systems for making it such a stimulating working environment with inspiring discussions and friendly atmosphere. A special thanks to Prof. Jan Lundgren for his encouragement and support along the way. I am also grateful to Clas Rydergren and Joakim Ekström for fruitful traffic discussions, Erik Bergfeldt and Vangelis Angelakis for the corresponding telecom discussions as well as Nils Breyer and Rasmus Ringdahl for all the interesting technical discussions.

I would also like to thank Prof. Alexandre M Bayen and Anthony D Patire at the University of California, Berkeley, Prof. Jaume Barcelo at Polytechnic University of Catalonia and Tomas Julner at the Swedish Transport Administration for a very inspiring collaboration over the years.

The research included in this thesis has been financed by the Swedish Transport Administration through the Centre for Traffic Research, the Swedish Governmental Agency for Innovation Systems (VINNOVA) and Norrköping Municipality.

Finally, I would like to thank all my family and friends for the support and inspiration you have given me. Thank you Sofia for all your support that made this possible and thank you Tim, Adam, Herman and Joel for being the best source of joy and inspiration!

Norrköping, October 2018

David Gundlegård 



\section{Contents}

INTRODUCTION .............................................................................................................

CELLULAR NETWORK SIGNALLING ........................................................5

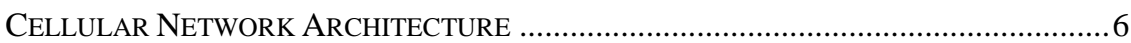

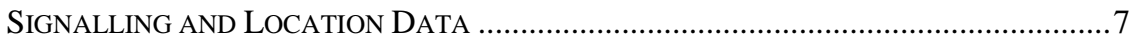

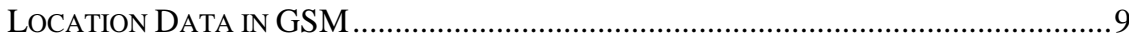

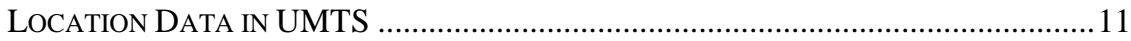

CELLULAR NETWORK POSITIONING_..................................................17

DATA COLLECTION PLATFORM AND PROCESSING PIPELINE .............23

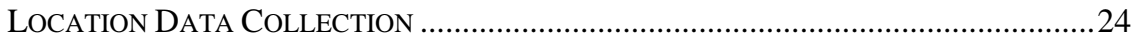

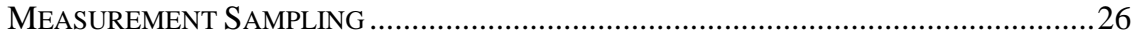

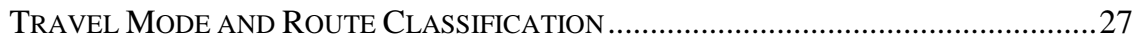

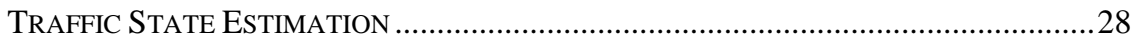

SPATIOTEMPORAL CHARACTERISTICS ..............................................31

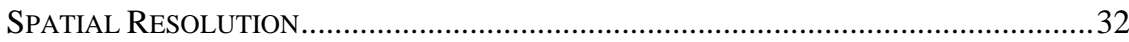

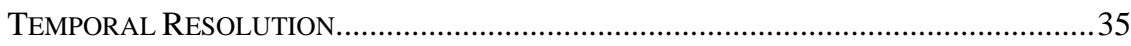

SENSOR FUSION AND MODEL ASSIMILATION ...........................................37

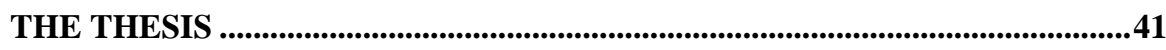

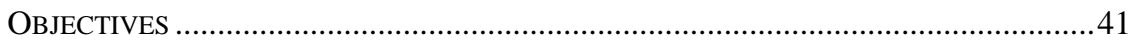

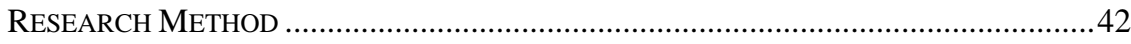

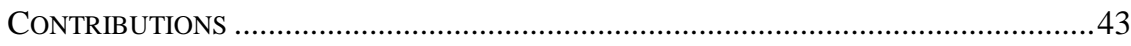

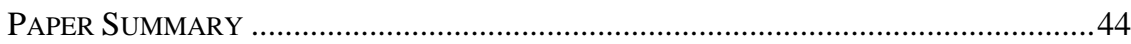

CONCLUSIONS AND FUTURE RESEARCH .......................................................... 48

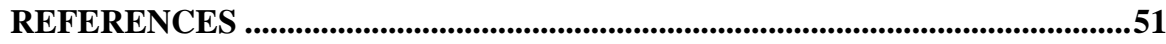

INCLUDED PAPERS ...................................................................................................59 



\section{Chapter 1 Introduction}

Road traffic congestion is a major issue in large cities all over the world. A standard solution to the problem is to increase the capacity by building new roads, but this is very costly and typically generates increased travel demand, which in turn have negative impact on the environment. A better option is to use the current transport infrastructure more efficiently by providing information and guidance to travelers, adaptive control of traffic or demand management techniques. To enable traveler information, traffic control and demand management we need information about the historic, current and future state of the transportation network. The traffic state is typically estimated and predicted using a combination of traffic sensor data and traffic models. To estimate the traffic state in terms of speed, flow or density on city level requires a large amount of traffic data and the sensor infrastructure for achieving this is very costly both to deploy and maintain.

The cellular network infrastructure is built to enable mobile communications with seamless coverage for wide areas worldwide and is available for more or less all populated parts of the world. If this infrastructure, together with the devices carried by citizens and mounted in vehicles, also can be used for the purpose of transport analytics, there is a large potential in making cost efficient monitoring of transportation networks as well as gaining better understanding of traffic dynamics and human mobility. Transport analytics is defined here as the discovery, interpretation, and communication of meaningful patterns in transport-related data. The meaningful patterns in data can further be used to e.g. observe travel demand as well as estimate and predict the state of the transportation network. 
The purpose of a cellular communication network is to offer mobile communication to subscribers of the system. In order to do this the mobile operator has to keep track of where in the network a certain subscriber is located. The location is used to reach the subscriber if it has incoming data transfers and to assign the subscriber to the most appropriate radio base station. The location within the network is communicated using signalling data, and with knowledge of the network structure, it can be transformed to a position of the subscriber. Hence, if we could use the cellular network signalling data to determine the position of subscribers at multiple points in time, we can use that to infer knowledge about mobility of different subscribers and the usage as well as the state of the transportation network.

The use of cellular network signalling data for estimating the state of transportation networks has been an active research area since mid 90:s [1]. The large demand of cost efficient traffic data in combination with the difficulty in getting access to data sets for research caused a lack of academic research in the area during the first decade. The difficulty in getting access to data sets for research was caused by major privacy concerns of the data in combination with very complex procedures for extracting data from the cellular networks. Another important challenge has been the difficulties for the mobile operators (that owns the data) as well as traditional traffic researchers to understand how the sparse and noisy data can be used in transport analytics. Although there has been a large improvement the last five years, it is still difficult to get access to data for verification, validation, algorithm design, parameter tuning etc. The NetMob ${ }^{1}$ conference dedicated to analysis of mobile phone data sets was an important step towards improved scientific work on cellular network data sets, and the $\mathrm{D} 4 \mathrm{D}^{2}$ challenges $[2,3]$ enabled a large increase in research on the topic. In [4], the number of publications based on cellular network signalling datasets over time, independent of application, is presented and it is clear that there has been a large increase in number of papers since 2010, when the first NetMob conference took place.

An important part missing in the D4D data sets, however, is the availability of other sensor data for validation and benchmarking of both different algorithms to process the cellular network data and the data characteristics of the data source itself. Most likely, the research area will expand significantly when the operators finally realize the potential in using this data for transport analytics and that it becomes part of the mobile operators' business models, which has happened recently in several places both in Sweden and in many other countries.

Although the technology of using cellular networks for road traffic state estimation has been subject for analysis for quite some time now, it is still far from being ma-

\footnotetext{
${ }^{1}$ www.netmob.org

${ }^{2}$ www.d4d.orange.com
} 
ture. It is not clear what to expect from these systems in terms of spatial and temporal resolution in the data that can be used for transport analytics. The potential of the system is although quite clear; it is possible to retrieve massive amounts of traffic data in a cost efficient way, i.e. by using existing signalling data without the need to invest time and resources in a sensor infrastructure.

Apart from the problem of getting access to datasets for research, there are several other challenges in using cellular network signalling data for transport analytics, the major ones being:

1) Extracting relevant data from the cellular network

2) Handling the noisy nature of the location data

3) Incorporating the new type of observations in traditional methods for transport analytics

4) Maintaining privacy of the cellular network subscribers

The overall aim of this thesis is to evaluate the potential in using cellular network signalling data for transport analytics and suggest new methods to help overcoming challenges 1) - 3) above. Challenge 4) can be handled by for example aggregation of data or adding noise to the data in different steps of the processing pipeline. A common method is based on the concept of "bring code to data", which means that the processing is performed close to the source, in this case the operators' internal network, and no data that can be connected to specific subscribers leaves this secure network. Even though challenge 4) is important, it is not in the scope of this thesis.

The remainder of this thesis is structured as follows. Chapter 2 gives an introduction to the signalling data that is available in cellular networks for the purpose of transport analytics. Chapter 3 describes how the signalling data can be turned into location estimates of mobile devices. Chapter 4 gives an overview of different methods for collecting signalling data from the cellular network, whereas chapter 5 describes the spatiotemporal characteristics of the collected data. Chapter 6 gives an introduction to how different types of sensor data can be fused and combined with models for traffic and mobility. Chapter 7 includes the thesis objectives, research method and contributions as well as a paper summary. Finally, the six papers of the thesis are included.

The introduction of this thesis contains parts from the book chapters Road Traffic Estimation using Cellular Network Signalling in Intelligent Transportation Systems [5] and Traffic Management for Smart Cities [6]. 



\section{Chapter 2 Cellular Network Signalling}

The general concept of public system architectures for mobile communication systems is a cellular network. The cellular networks are built based upon a number of small geographical areas, cells, covering a larger area. Each cell consists of a base station transmitting the information within the limited area. For analytical purposes these areas are sometimes represented as hexagonal cells, which is the uniform tessellation method that is most similar to real transmission patterns. Note that this a major simplification which is discussed in more detail in Chapter 4.

Signalling data is the extra data generated in communication networks in order to support successful transfer of user data. The signalling data is not relevant for the end user, it is only generated to support the functionality of the communication network. Many different types of signalling data are generated in cellular networks, it can be related to flow control, error control, power control etc. However, an important function of cellular networks is to handle mobility of users in the network, and the signalling data generated for this purpose is of main interest in this thesis.

Figure 1 shows a road segment and the cells covering the area as an example of how a road segment crosses several cells in its path and the signalling data generated when a device changes from one cell to the next (makes a handover) was the concept that laid ground for the initial work on cellular network signalling data for travel time estimations. Currently, not only handovers are used as input and travel times are not the main output, which is discussed in more details in Chapter 3. 


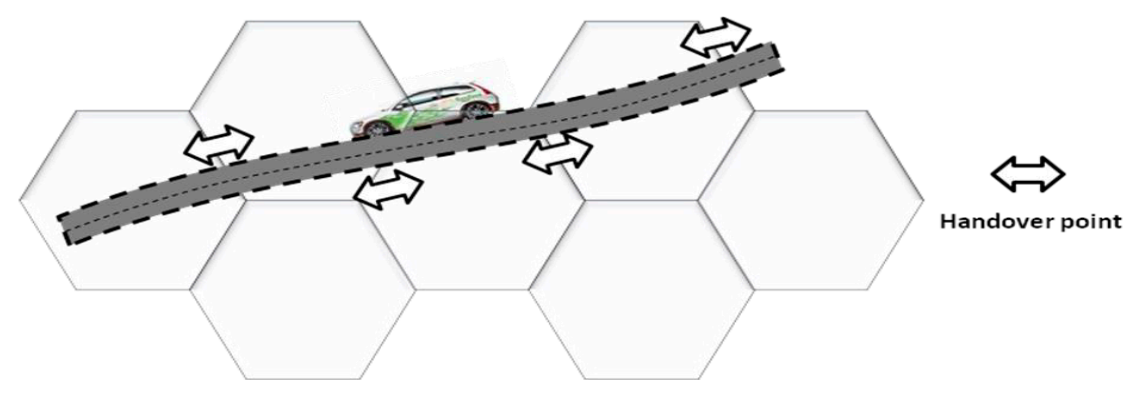

Figure 1. Travelling on a road segment involves a large number of cell border crossings. The handover between the cells can be used to estimate traffic information and can be seen as virtual detectors.

\section{Cellular Network Architecture}

Different types of signalling data is generated between different components in the cellular network and the architecture of cellular networks is here described to enable a better understanding of the flow of signalling data in a cellular network. The focus of the thesis is on signalling data in GSM and UMTS networks, and the remainder of this chapter will go into more details of the network architecture and signalling data for these types of networks.

The system architectures for both GSM and UMTS are rather similar in their concept. An overview of the system architectures are to be found in Figure 4. A GSM Base Transceiving Station (BTS) holds the transmit and receive equipment for one or more cells. It constitutes the interface between the network provider and the mobile phone. The Base Station Controller (BSC) administers the transmit and receive resources of the connected base stations. There are two categories of channels, signalling and traffic channels. Both the signalling channels and the traffic channels (handling the actual payload) are processed here. Also the data traffic between all the BTS's and the Mobile Switching Centre (MSC) is supervised and controlled in the BSC. The concept for UMTS is rather similar, the base station is here called Node B and the device controlling a number of these Node B:s is denoted Radio Network Controller (RNC). Figure 4 also provides the interfaces between different sections of the architecture. The interface between the BTS and BSC in GSM is denoted $\mathrm{A}_{\text {bis, }}$ and the corresponding interface in UMTS is denoted $\mathrm{Iub}_{\mathrm{ub}}$. The interface between the GSM systems radio parts and the core network $(\mathrm{CN})$ side is denoted A and the corresponding interface for UMTS is denoted $\mathrm{I}_{\mathrm{u}}$.

After this stage, i.e. interface $\mathrm{A} / \mathrm{I}_{\mathrm{u}}$, we find the devices that connect to other networks. If the communication should go through the circuit switched network side, it uses the MSC. The MSC carries out all the duties of an ordinary wireline network 
switch, such as processing, finding a path and supplementary services. It is also the link between the wireless networks and the wireline network. If the communication is more data oriented it would go through the packet switched network side and hence through the Serving GPRS Support Node (SGSN). In Figure 4 both devices are connected to the "network", it should be pointed out that this is just a simplification and is in reality a number of different networks with different network features and service level agreements.

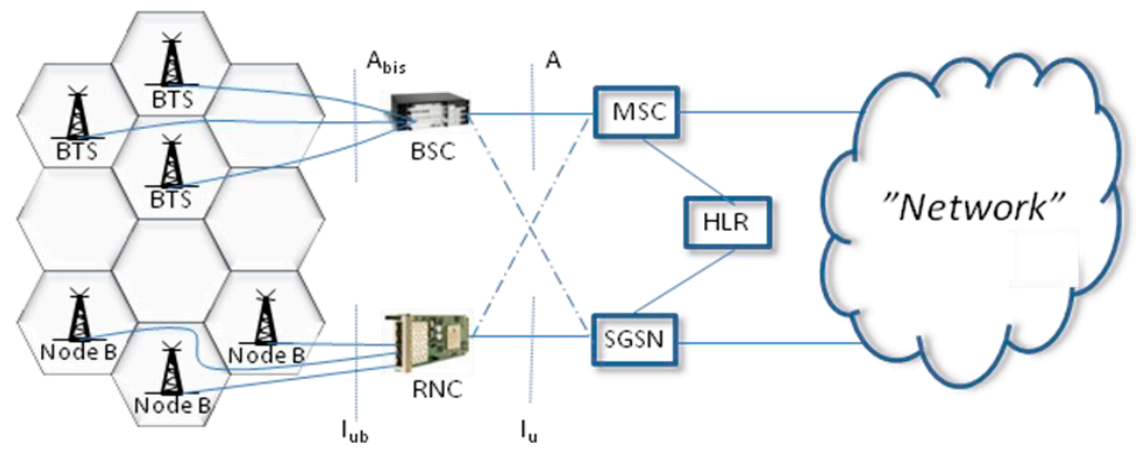

Figure 2. The cellular network architecture for the GSM (upper part) and UMTS (lower part) and their connection to the core network through the $\mathrm{A}$ and $\mathrm{I}_{\mathrm{u}}$ interface, respectively.

\section{Signalling and Location Data}

When estimating subscriber movements to enable understanding of transportation networks and human mobility two types of signalling data is of special interest; signalling data related to location management and radio resource management. The aim of location management is to keep track of the location of a mobile terminal in the network to support routing of incoming data transfers or telephone calls to the mobile terminal. Location management is performed for all mobile terminals in the network and is handled in the core network or the network switching subsystem (NSS) (see Figure 3). The aim of radio resource management (RRM) is to maintain the connection of the mobile terminal when moving in the network, and an important part of this is to decide to which cell(s) to be connected to at each time instant. RRM is performed for all active terminals and is handled in the radio network or radio station subsystem (RSS) (see Figure 3).

The characteristics of the data generated by cellular networks in the context of transport network analysis depends on a number of things, for example the type of network, the network configuration, the type of devices using the network and the traffic patterns of subscribers in the network. However, a very important part is also where in the cellular network the data is collected. Figure 3 gives a simplified over- 
view of a cellular network with information about which type of data that can be collected in the different parts of the network.

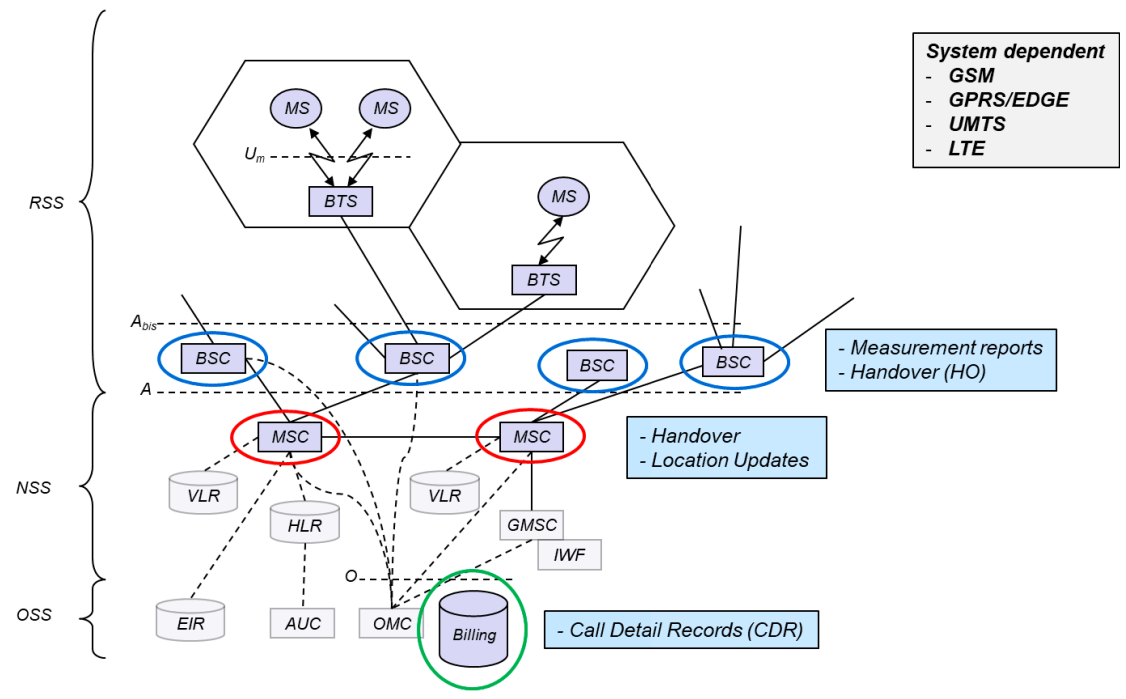

Figure 3. Example of cellular network architecture with information about where in the network the different types of signalling data is available.

We categorize the signalling data from cellular networks related to transport analytics in the following types:

- Billing data

- Location updates

- Handovers

- Measurement reports

- Dedicated location data 
Billing data is data stored by the mobile operator for billing purposes. This data is always stored by the mobile operator and is relatively easy accessible in the network. Standard billing data are often denoted Call Detail Records (CDR), which typically includes subscriber id, cell id and timestamp for all telephone calls and SMS. When also data connections are included in the billing data the same data is available also for the times when the phone is connected to Internet, this data is sometimes referred to as $\mathrm{xDR}$ and the exact timing of these seem to vary a lot between different operators.

Location updates are principally signalling data generated to support location management and this type of data can be further divided into cell updates, Location Area (LA) updates, Routing Area (RA) updates, UTRAN Registration Area (URA) updates, Tracking Area (TA) updates and periodic updates. LA, URA, RA and TA are a set of cells grouped together and if the location is updated per cell or for which grouping it is updated depends on the type of network used and the state of the terminal in terms of data transfer. Periodic updates are different from the rest since it is triggered by an expired timer, rather than a movement between geographical areas. This also means that except for the periodic updates, which can occur anywhere in a geographical area, all other location updates are performed on the border between the different geographical areas.

Handovers are cell changes triggered by RRM functions in the network and are most often expected to be performed on the border of cells. The difference between cell updates and handovers is small, but here we define handovers as cell changes initiated by the network and cell updates as cell changes initiated by the mobile terminal. Handovers are mainly used for active telephone calls and cell updates are mainly used for ongoing data sessions, but in some cases, the network initiates cell changes for data sessions as well.

Measurement reports of current and neighbouring cells are sent by the mobile terminal to the radio network in order to support handover decisions made in the network side. These measurements are sent with a high frequency and can be used to estimate mobile terminal location with a much higher resolution in time and space compared to billing data, location updates and handovers.

Dedicated location data can be generated by the mobile terminal for the (sole) purpose of locating the device. These measurements are typically not needed for the standard RRM functions and hence generate overhead in the system, but also give the possibility to locate the device with much higher accuracy than for the standard measurement reports. Examples include time differences between system frame numbers (SFN-SFN time differences) or round-trip times (RTT).

The remainder of this chapter describes the location data available in specific systems in more detail. More details in GSM and UMTS specific characteristics can be 
found in the referenced 3GPP standards [7-12]. A good overview can also be found in [13].

\section{Location Data in GSM}

For travel time estimation the signalling data generated by users in busy state, i.e. during voice calls or data sessions are mainly used. This signalling data generated by busy state terminals is in GSM handled by Radio Resource Management (RRM) algorithms located in the radio access network. Complementary data can be obtained from positioning functions in the network or signalling data generated by idle state terminals. Signalling data of idle state terminals is handled by Mobility Management (MM) algorithms located in the core network.

RRM is only active when the terminal is in busy state and an important task of RRM is to initiate handover. The Base Station Controller (BSC) is responsible for the handover decision and use information from measurement reports sent by the terminal and the current Base Transceiver Station (BTS). This information is very useful in the process of tracking a terminal. The terminal and the BTS repeatedly send information about received signal strength (RXLEV) and signal quality in bit error rate (RXQUAL). The fields are 6 bits long and correspond to a resolution of 64 discrete values. The terminal measures the signal quality and strength on the downlink and the BTS measures the signal quality and strength on the uplink. Based on the neighbouring list that is broadcasted by the BTS, the terminal tunes in to neighbouring cells and measures the signal strength. From the terminal, measurement reports are sent on the Slow Associated Control Channel (SACCH) once every $480 \mathrm{~ms}$, the BTS adds the uplink measures and forwards a measurement result to the BSC.

Due to the propagation delay from the mobile terminal to the BTS, the terminal has to start its transmission earlier in order to avoid interference on adjacent timeslots. How much earlier the terminal shall start its transmission is calculated in the BTS and the terminal is informed via a timing advance (TA) value that is sent on the SACCH to the terminal. The TA field is 6 bits long and corresponds to a resolution of $550 \mathrm{~m}$. The TA value can also be used by the BSC in the handover decision and is included in the measurement report from the terminal. The BSC can use the TA value to roughly estimate the terminals velocity and, if a hierarchical cell structure is used, assign highly mobile terminals to a cell on a higher level. The TA value is also important for the BSC to complement the signal strength measurements in order to determine to which cell the terminal should be handed over. 
When the terminal is in idle mode, i.e. powered on but not used for voice calls, data sessions or signalling, MM algorithms in the core network keep track of in which part of the network the terminal is located. The location information of a terminal in idle mode is sparse compared to when in active mode and has the resolution of a Location Area (LA), which consist of a configurable number of cells. The mobile terminal sends an LA update message when it detects a new LA identity broadcasted by the currently strongest BTS. During the LA update the terminal goes into busy state and more location information can be retrieved during a short period of time. A detailed description of GSM MM and RRM can be found in e.g. [14]. The relation between standardised location data reports and magnitudes of sampling distances is shown in Figure 4.

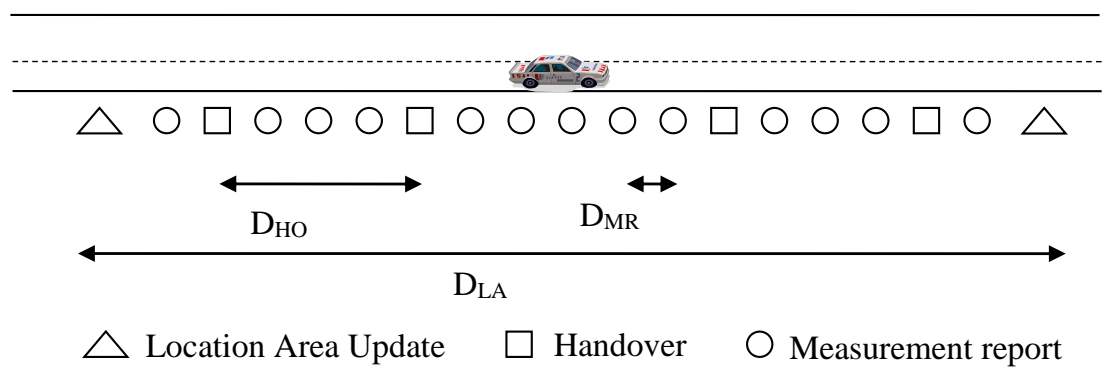

Figure 4. Distance between location data reports in GSM. $\mathrm{D}_{\mathrm{LA}}$ is the distance between location area updates (magnitude from several $\mathrm{km}$ up to several tens of $\mathrm{km}$ ). $\mathrm{D}_{\text {но }}$ is the distance between handovers (magnitude from several hundreds of meters up to several kilometres and even several tens of $\mathrm{km}$ in rural areas). $\mathrm{D}_{\mathrm{MR}}$ is the distance between measurement reports (magnitude from several meters up to several hundreds of meters).

A GPRS-attached terminal does also generate location data, the information is however slightly different from circuit switched GSM data. When the terminal is attached to the GPRS network it can be in two mobility management states, stand-by or ready state. When the terminal is in ready state it can send and receive user data. A major difference between GPRS ready state, compared to circuit switched busy state, is that the terminal itself is responsible for which BTS to communicate with (mobile evaluated handover) [10]. The terminal listens to neighbouring cells during packet transfer and decides if it should stay with the current BTS or change to a better one. In ready state cell identity, TA-value and signal strength to the serving cell is useful location data. Since mobile evaluated handover is used in default mode, the terminal does not report signal strength to surrounding cells in ready state and hence this information cannot be used for tracking the terminal. However, the network can instruct 
the terminal to send measurement reports if necessary. In stand-by state the terminal is connected to the GPRS network, but is unable to send user data. In stand-by state the terminal only performs Routing Area (RA) updates. A RA comprises one or more cells and is comparable to, but not the same as LA, see Figure 5 for a schematic view.

\section{Location Data in UMTS}

As for GSM networks, the mobility of terminals in UMTS networks is handled by MM and RRM functions. MM and RRM are implemented in a similar manner in both systems, there are however a couple of fundamental differences. In UMTS RRM is solely handled by the UMTS Radio Access Network (UTRAN), this is achieved by connecting the Radio Network Controllers (RNC) with each other. Another important difference between the systems is that the support for Quality of Service (QoS) for different service classes in UMTS calls for more adaptive MM. This is solved by implementing MM functions not only in the core network, but also in UTRAN. More information regarding UMTS MM and RRM can be found in e.g. [15-16].

In both GSM and UMTS the MM state of the terminal decides how much location information that is available. The MM state model in UMTS reminds a lot of the one used in GSM/GPRS, although the UTRAN MM adds a number of new states. Principally, the location of the terminal in UMTS is known on cell level and mobile assisted (network evaluated) handover (MAHO) is used when the terminal is used for a service with high QoS demands (e.g. speech or a high bit rate data session). When the terminal is switched on but not used for data transfer it is known on LA or RA level. When the terminal is used for low bit rate data transfer it is known on cell or UTRAN Registration Area (URA) level depending on mobility. 


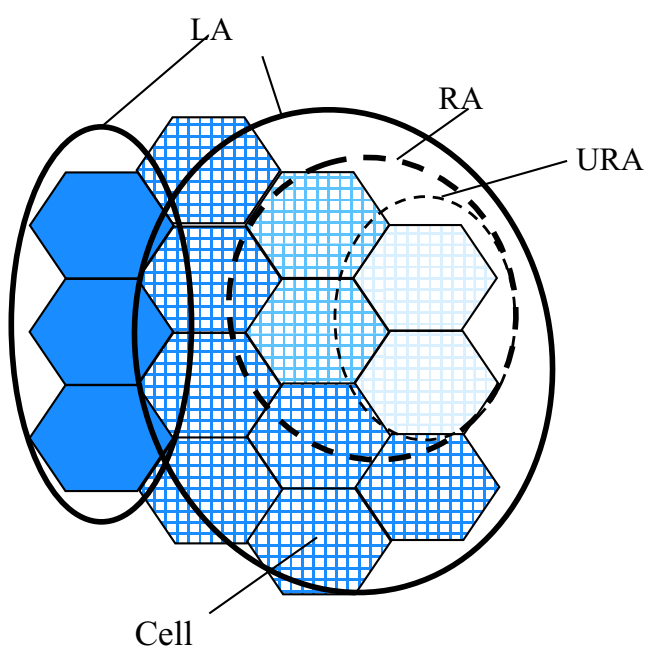

Figure 5. Relation between Location Area (LA), Routing Area (RA), UTRAN Registration Area (URA) and cell.

The location of the terminal is known in most detail when the terminal is used for circuit switched services or high speed data services, i.e. when the UTRAN MM state is Cell DCH (Dedicated Channel). In this state MAHO is used, which means that the terminal continuously reports data about the radio connection that can be used to locate the terminal. This state is similar to busy state of circuit switched GSM. The RRM of the two systems are however quite different, which leads to a number of important differences in available information. The main differentiating characteristics of UMTS RRM compared to GSM are:

- Handover control

- Time alignment

- Power control

These functions will affect the available information of a connection. The most important difference in handover control is the use of soft handover in UMTS. This means that the terminal is connected to several base stations at the same time which means that the location of the terminal can be determined in more detail. The terminal is expected to be in soft handover during $20-40 \%$ of the time [16]. Another difference in handover control is how the network makes the handover decision, i.e. the characteristics of the measurement reports that are sent from the terminal and the base station to the RNC.

In UMTS the periodic measurement report interval is configurable between 0.25 and 64 seconds, depending on radio environment and the state of the mobile terminal 
[17]. The frequency of event triggered reports are dependent of the frequency of actual events, e.g. a new radio link addition to the active set, but also on the operator configurable parameters time-to-trigger, hysteresis and offset value. More detailed information on UMTS measurement reports can be found in e.g. [12, 16, 17]. Signal strength and quality of serving base station(s) are similar to the ones in GSM. The maximum number of surrounding base stations that can be measured is increased from 6 in GSM to 32 in UMTS. A TA value is not calculated in UMTS (WCDMA) networks since it is not a TDMA based system, but other time alignment measurements are available, e.g. round trip time and time difference between base stations [12].

The soft handover used in UMTS means that a terminal can be connected to several base stations simultaneously, whereas in GSM the terminal is only connected to one base station at the time. To track a vehicle, both measurement reports containing radio parameters and handover points can be used. When it comes to calculating travel times it is very important to have two accurate estimations of the vehicle's position in order to make a good estimate of the travel time between those points. The handover points in GSM are a good candidate to estimate those positions. However, in UMTS the terminal will not change from one base station to another, instead radio links will be added to and removed from the terminals active set.

A potential problem with travel time estimation is the use of cell breathing, which probably will be more utilised in UMTS than in GSM. In cell breathing the size of the cells can change dynamically depending on the capacity need of different areas. An important tool to determine travel time is to measure the time between handover points, and if cell breathing is used the handover points will change with time. It will hence be more difficult to predict the handover points based on observed handover events, but the pilot power of the base stations is known and can be used as input for the predictions.

An important function of the Carrier Division Multiple Access (CDMA) based systems is fast power control. In UMTS the inner loop power control makes it possible to adjust the terminal's power level 1500 times per second [16]. This can be compared to approximately two times per second in GSM. This means that the power level between the terminal and its serving base station(s) is measured at least 1500 times per second, and hence a massive collection of data is available. This data can be used to locate the terminal relative the connected base station(s) and be useful in the travel time estimation. However, a potential problem is that the inner loop power control is performed in the base station, which means that the information is not available in the RNC where it is viable to collect it. The RNC is though responsible for the outer loop power control, i.e. to control the target signal to interference ratio (SIR), which has a frequency of $10-100 \mathrm{~Hz}[16]$. 
Measurement reports to support handover and power control will be useful in order to locate the terminal according to relative received power level from different base stations. Power levels might not be the most efficient measurement to use when a terminal shall be located; this is due to fast and shadow fading. More often time differences are used to calculate the position of a terminal, which leads us to the time alignment comparison of UMTS and GSM. As described, time alignment is important in GSM and is managed with the TA-value calculated by the BTS and sent to the terminal. Since UMTS is a CDMA based system, the time alignment is not needed in order to avoid co-channel interference and is not implemented. However, similar time-alignment measurements are also available in UMTS.

During soft handover it is important to minimize the buffer needed in the terminal to combine the signal from the base stations. To do this, the terminal measures the time difference between the base stations and sends this information to the network, which compensates for this by time alignment of the base station signals. The time difference is measured in terms of time difference between the system frame number (SFN) of different cells and is often referred to as the SFN-SFN time difference. If we know the real-time difference between the base stations, which can be measured by base stations or location measurement units (LMUs), we can narrow down the position of the terminal relative the base stations (cf. TDOA positioning). Another possibility is to use the round-trip time (RTT) measurements calculated by UTRAN. Reference [4] states that the RTT should have a measurement period of $100 \mathrm{~ms}$ and an accuracy of \pm 0.5 chips. One chip accuracy in time correspond to approximately 80 $\mathrm{m}$. Reference [18] claims, however, that it is possible to measure RTT with the accuracy of $1 / 16$ of a chip, which corresponds to approximately $5 \mathrm{~m}$.

So far, terminals in Cell DCH state have been discussed. However, terminals in Cell Forward Access Channel (FACH) and Cell Paging Channel (PCH) state will be very useful in travel time estimations since the terminal performs cell updates in both of these states. Depending on the size configuration of URA, also terminals in URA $\mathrm{PCH}$ state might produce useful information. Terminals in these three latter states are characterised by having small amounts of data with low QoS demands to transfer [15]. If the URA is configured to be large, the information from URA updates can be used for the same purpose as RA or LA updates, e.g. as input for O-D matrix estimations or traffic flow measurements over large areas.

Another fundamental difference between UMTS and GSM is the physical layer implementation. The characteristics of the modulation and wide spectrum of UMTS make it more suitable for positioning [19]. These characteristics may also affect the possibility to estimate the speed of the terminal according to the reception properties of the signal. This type of speed estimation can be useful in estimating travel times; it 
will however depend on implementation of the technique in the cellular networks. Different solutions to do this are described in [17-19].

The physical layer implementation also calls for another crucial characteristic of UMTS compared to GSM, in general significantly smaller cells. A denser network of base stations makes the location accuracy better, both in terms of active and passive monitoring as described in the following sections.

Table 1. Location data relevant for road traffic information estimation in GSM and UMTS networks.

\begin{tabular}{|l|l|l|}
\hline & \multicolumn{1}{|c|}{ GSM } & \multicolumn{1}{c|}{ UMTS } \\
\hline $\begin{array}{l}\text { Synchronisation level } \\
\text { [bit length in m] }\end{array}$ & 1108 & 78 \\
\hline Time alignment & TA & RTT/SFN-SFN \\
\hline Cell size & $<35 \mathrm{~km}$ & $<10 \mathrm{~km}$ \\
\hline Registration areas & LA/RA & LA/RA/URA \\
\hline $\begin{array}{l}\text { Measurement report } \\
\text { interval }\end{array}$ & Periodic $0.48 \mathrm{~s}$ & $\begin{array}{l}\text { Periodic } 0.25-64 \mathrm{~s} \\
\text { Event-triggered }\end{array}$ \\
\hline $\begin{array}{l}\text { Max number of cell } \\
\text { measurements }\end{array}$ & 6 & 32 \\
\hline $\begin{array}{l}\text { Power control frequency } \\
\text { 2.1 Hz }\end{array}$ & $\begin{array}{l}\text { Inner loop: } 1500 \mathrm{~Hz} \\
\text { Outer loop: } 10-100 \mathrm{~Hz}\end{array}$ \\
\hline
\end{tabular}




\section{Chapter 3 \\ Cellular Network Positioning}

As described in the previous chapter, the availability of positioning data for mobile terminals is different depending on type of network, the state of the terminal, the users' preferences and the geographical location. In order to use the signalling data for inference of mobility of mobile terminals in the network, and consecutively the state of transport networks, the signalling data needs to be turned into location estimates. In this section, we will give an overview of methods to use in order to turn location related information in signalling data to estimates of the mobile terminal location. For an extensive treatment of general positioning technologies and methods, see e.g. [13] and for cellular positioning, see e.g. [23].

A standard classification of cellular positioning methods is to relate the method to which extent the network and the terminal is involved in the positioning process. The different categories are network-based, handset-based and handset-assisted.

- Network-based positioning

Positioning within this category rely on measurements and calculations made by nodes in the cellular network. This imply that all positioning related functionality is located in the network and that all the processing is carried out by the network. An important result of this characteristic is that the network-based positioning methods supports legacy terminals, i.e. no changes has to be made to existing terminals. Network-based positioning implies multilateral positioning, i.e. the terminal transmit data that is received by one or several network nodes. Hence, a drawback of networkbased positioning is that the terminal needs to be in active mode in order for a posi- 
tion to be calculated. Since the cellular network determines the position of the terminal, it also falls into the category of remote positioning.

- Handset-based positioning

These kind of positioning methods rely on positioning measurements and calculations made by the terminal. This implies that terminals are required to be updated with positioning functionality that is not supported in legacy terminals. The main advantage with handset-based positioning is that the terminal does not need to transmit in order to calculate a position, instead unilateral positioning is used, i.e. the terminal receives signals sent by multiple network nodes and use these for positioning. Since the terminal calculates its own position, handset-based positioning can also be referred to as a self positioning method.

- Handset-assisted positioning

Sometimes it is more convenient to use a unilateral approach and let the terminal report measurements to the network, where the position is calculated. If standardised measurements are used, e.g. signal strength or timing advance, legacy terminals can be used for positioning and additional functionality is not necessary in the radio access part of the network. Like network-based positioning, this is regarded as a remote positioning method. It should be noted that remote positioning can be performed with handset-based methods by letting the terminal transmit the calculated position to the network, this is referred to as indirect remote positioning. Using the same idea, self positioning can be performed with network-based positioning, and this is referred to as indirect self positioning.

After making a distinction between where and how the measurements are performed, we will now focus on the methods used to estimate the location. Generally, we can solve the location estimation using methods based on regression or classification. Traditionally regression-based, or geometric, methods have been mostly used for location estimation, but recently there has been a large focus on using pattern recognition based methods that treat the location estimation problem as a classification problem, i.e. determining the most likely location given a discrete set of possible locations.

The most trivial classification method is based on the knowledge that the target is within a certain area. For example, once a base station register a terminal we know it is within the radio coverage of that base station and if we use only the information about which base station the mobile terminal is connected to it is known as proximity sensing. The accuracy of proximity sensing depends on the base station coverage as 
well as the cell coverage representation, which is discussed in more detail in Chapter 4.

To improve the estimate from proximity sensing a common method is to use regression-based methods using distance or distance difference observations. The former is referred to as circular lateration or time-of-arrival (TOA) and the latter hyperbolic lateration or time-difference-of-arrival (TDOA). In circular lateration the distance to a known position is known and hence we could draw a circle around this position. If we do that using one more known distance from another position we will get another circle with two intersections and hence two possible locations. The addition of a third measurement gives a unique position estimation in two dimensions. This corresponds to solving a system of equations on the form:

$$
r_{i}=\sqrt{\left(x-x_{i}\right)^{2}+\left(y-y_{i}\right)^{2}}
$$

where $r_{i}$ is the range observation between the mobile terminal and base station $i$, [ $x_{i}$, $\left.y_{i}\right]$ are the coordinates for base station $i$ and at least three equations are needed to solve the problem for two dimensions. The nonlinear equation system can be solved efficiently using iterative methods like gradient descent or by using equation symmetry to transform the set of $n$ nonlinear equations to $n-1$ linear equations.

If we are only able to calculate the difference in time of arrivals of the same signal at several points we obtain a hyperbolic. The crossing of two or more hyperbolics becomes the positioning estimate (requires at least three reference stations). The advantage of using time differences is that no synchronisation between the terminal and reference station is required, on the other hand synchronisation between reference stations is required instead. For hyberbolic lateration the system of equations will have the following form:

$$
r_{i j}=\sqrt{\left(x-x_{i}\right)^{2}+\left(y-y_{i}\right)^{2}}-\sqrt{\left(x-x_{j}\right)^{2}+\left(y-y_{j}\right)^{2}}
$$

where $r_{i j}$ is the distance difference between base station $i$ and $j$ and at least two equations are needed to solve the problem in two dimensions. Also this equation system can be solved using standard iterative methods.

The distance between mobile terminal and each base station can be estimated using propagation time measurements in combination with knowledge of the wave propagation speed. However, it is also possible to estimate the distance based on path loss observations in combination with radio propagation models.

Another method to estimate the location is to use angulation. This method is only applicable if either side is equipped with antenna arrays and hence able to detect from which approximate direction the signal is arriving. With several such sites, the termi- 
nals position estimate is restricted to a line that crosses both the target and the base station. The intersection of several of these lines becomes the positioning estimate. This method is sometimes also denoted Angle of Arrival (AOA) and Direction of Arrival (DOA). The system of equations will then have the form:

$$
\alpha_{i}=\arctan \left(\frac{y_{i}-y}{x_{i}-x}\right)
$$

where $\alpha_{\mathrm{i}}$ is the direction if the incoming signal from base station $i$ and at least two measurements are needed to solve the problem in two dimensions.

Pattern matching, or fingerprinting, is a method that has become popular lately, probably both due to the easy availability of signal strength measurements in combination with increased computing power when estimating the location. Pattern matching methods in the context of location estimation are very generic and can principally be used as soon as we can collect sensor observations that are correlated to the location of the mobile terminal. Any type of sensor observation with correlation to location, including distance and angle measurements described previously, can be used to generate the patterns for comparison, but for cellular network positioning received signal strength is the most widely used. The idea is to compare measured patterns with predefined patterns tagged with known location data and find the most similar pattern with respect to some distance definition or loss function between the measured and predefined pattern. The predefined patterns can either be previous sensor measurements with known location, or predicted using e.g. radio propagation models for the case of received signal strengths. The similarity of patterns is often described on the form:

$$
d_{k}=d\left(m, f p_{k}\right)
$$

where $d()$ is some distance operator and $d_{k}$ is the distance between the measured pattern $m$ and the k:th predefined pattern, often denoted fingerprint, $f p_{k}$. The tagged location of the fingerprint with the shortest distance to the measurement is chosen as the location estimate.

For many applications, the use of dead-reckoning or inertial navigation based on data from local sensors like accelerometers or gyroscopes can be very useful to improve location accuracy and coverage. However, these kind of local sensors are not likely to be used in either mobility management or radio resource management of cellular networks, and are hence not described further here.

There are a number of the cellular positioning methods that are more or less standardised and in use today. For example the CGI-TA (Cell Global Identity-Timing Ad- 
vance) gives information in which cell the terminal is situated and how far from the base station, i.e., a circle on which the terminal could be at any point. In the case the cell is divided into sectors we will also receive in which sector of the cell the terminal is situated. The precision of this method is coarse, however, all information already exist in the network. The corresponding method in UMTS is Cell ID-RTT (Round Trip Time). Another used method is Enhanced Observed Time Difference (E-OTD), which is based on unilateral TDOA positioning. E-OTD requires the involved three base stations to be synchronized and additional hardware in the network as well as updated cell phones. The UMTS method corresponding to E-OTD is called Observed Time Difference of Arrival (OTDOA). The multilateral versions of E-OTD and OTDOA are called Uplink TDOA (U-TDOA) in both GSM and UMTS. The TDOAbased positioning methods typically have better accuracy than e.g. CGI-TA, however, more processing, updated cell phones and new hardware is required. Also Assisted GPS (A-GPS) is standardised in GSM and UMTS for high precision positioning, these standards rely on a GPS receiver in the cell phone. More information regarding these methods can be found in e.g. [6-7]. In LTE standardisation efforts are made for the E-CID and OTDOA methods [24]. Also the Adaptive enhanced cell id (AECID) method [25] seems to be a potential fingerprinting-based method for standardisation in LTE networks. 



\section{Chapter 4 \\ Data Collection Platform and Processing Pipeline}

There are relatively few papers available in the literature that describe data collection platforms and processing pipelines for the use of cellular network signalling data in transport analytics. Some early exceptions are Zhi-Jun Qiu et al. at University of Madison Wisconsin, see e.g. [26-30], and Bruce Hellinga et al. at University of Waterloo, see e.g. [31-33]. More recent examples include [34] for traffic flow estimation, [35] for travel time estimation and [36] for OD estimation.

In order to estimate road traffic information from cellular networks the following basic steps can be included:

1. Location data collection

2. Measurement sampling

3. Travel mode and route classification

4. Traffic state estimation

The location data collection phase involves how to gather the relevant data from the cellular network. The available data is described in Chapter 3. Measurement sampling is the process of finding moving terminals and for the case of OD estimation and travel statistics detect when trips have been made. For the case of travel time estimation it is about finding out when travel times should be sampled. The travel mode and route classification phase includes how to infer travel mode and travel route based on the data available for each trip or travel time sample. The last step is to perform the traffic state calculation. Depending on the traffic data that is of interest, e.g. 
long term traffic flows, OD matrices, travel times, route choices or incident detection, different approaches and location data will be used. The steps can be carried out in a different order, in combination with each other and there can also be iterations between the different steps.

\section{Location Data Collection}

In early work, two different approaches were distinguished when collecting location data from the cellular networks. The first approach was based on the Federal Communications Commission (FCC) mandate that all mobile phones should be possible to locate with certain accuracy. A similar agreement exists in the EU countries and the operators active in EU. This implies that mobile phones can be located periodically and hence an average speed can be determined for moving terminals. This approach has the drawback that it generates extra traffic in the network and might be more vulnerable to privacy issues. The second approach relies on monitoring the generated signalling traffic data without trying to explicitly locate any of the mobile phones. The first approach is referred to as active monitoring whereas the second is referred to as passive monitoring.

Active monitoring can use any of the standardized positioning technologies described in Chapter 3, e.g. CGI-TA or E-OTD. In passive monitoring it is possible to use all the data generated by the terminal to track a vehicle, this data is also described in detail in Chapter 3. The problem with the passive monitoring approach is that terminals only generate detailed location information in busy state. This reduces the number of available probes significantly compared to all mobile phones that are switched on. This problem has reduced significantly with the introduction of smartphones, which are active very often without user interaction for the purpose of updating email clients, weather widgets etc. in the background. The hybrid approach is based on passive monitoring with the possibility to complement with active monitoring upon certain criteria, e.g. large variations in estimations and light network load.

The possibility of estimating road traffic information with the help of cellular communication networks is well known, although the technique is not widely used today. Several commercial solutions are available, early examples include CellInt, AirSage and TrafficCast. Commercial companies, public organizations and universities have carried out field tests and simulations in order to evaluate the possibilities of the technology. A number of tests have been carried out in the U.S., but early field tests were also carried out in for example Austria, Canada, China, Finland, France, Germany, Israel, the Netherlands and Spain, see e.g. [37-44].

The Cellular Applied to ITS tracking And Location (CAPITAL) project was one of the first attempts to exploit cellular data to extract traffic information. The operational project started in 1994 in Virginia and ran for 27 months. The system used 
TOA together with AOA positioning to actively monitor different subscribers. The solution is based on active monitoring and it was unable to extract any useful information [1]. Since then a lot of experience has been made in field tests and simulations and a number of projects have reported promising results.

The projects following CAPITAL have taken many different approaches to extract information from the cellular networks. Early papers in the area are mainly focused on the active monitoring approach. In addition, the developed simulation models are based on this approach. Reference [45-46] use simulation to evaluate the impact of system parameters, e.g. sampling interval, positioning error etc., in active monitoring based systems. Also [47] is an active monitoring based simulation model, and the focus is to evaluate a segment based approach to estimate travel times.

A number of papers assume configurations to the cellular network in order to generate more detailed signalling traffic [48-52]. These systems will be able to estimate the traffic conditions better than standard passive monitoring systems, but it is not obvious that the signalling configurations ever will be implemented in a commercial cellular network. A couple of field tests have been carried out where cell phones are altered in order to send location and speed data with regular intervals, it is important to distinguish these tests since they require user acceptance and special software and is maybe better categorized in the area of regular floating car data (FCD). It is possible that also active monitoring will require user acceptance since arbitrary switched on cell phones can be tracked and the tracking actually drains the terminal battery.

Due to an increasing number of mobile terminals on the roads that generate useful data, a wish to minimize network load and better tracking algorithms, the passive monitoring approach has gained popularity, and is to date the absolutely most widespread technique. Several ways of passively collecting signalling data from the network are proposed in the literature. The first one is based on analysis of billing information sent from the core network. This approach is used in e.g. [39, 53] and makes it easy to collect the data typically at a single interface for the whole network. The billing information is not as detailed as the information available in other parts of the network and therefore systems are proposed using either the A- or $\mathrm{A}_{\text {bis-interface of }}$ the GSM network. If the A-interface is used, fewer installations have to be made for a certain geographic area. On the other hand the available location data is not as detailed as in the Abis-interface. Basically the difference is that in the A-interface only handover and location area updates can be used, whereas in the $\mathrm{A}_{\text {bis-interface also }}$ measurement reports can be used to estimate the location of the terminal. Passive monitoring via $\mathrm{A}$ - or $\mathrm{A}_{\text {bis }}$ interface is used in e.g. [40, 54, 55].

The natural extension to use either active or passive monitoring is to combine these two approaches; this is also suggested in commercial systems [56-58]. It is, however, unclear from present publications if it has been evaluated in a field test. 
This approach makes it possible to gather more information when it is most useful without putting unnecessary load on the network.

To date, principally all commercial systems and field tests are based on passive monitoring. Traditionally, either billing data or signalling data from the core network are used as input. However, the last years there has been an increased interest in processing also data from the radio network for a large number of users and process that data in platforms for dedicated cellular positioning. This still puts significant load on the operator platforms for location data extraction, but it is likely that we shortly will see more of this type of data being used also within transport analytics.

\section{Measurement Sampling}

Large amounts of signalling data is generated in a cellular network. However, for the purpose of transport analytics we are mainly interested in tracking the terminals that are using the transportation network. Note that for some applications it can also be interesting to analyse pedestrian trips and mobility patterns, but this requires special treatment and whether it is possible to distinguish pedestrian trips or not will depend on the type of data extracted from the cellular network. For some applications, it is also interesting to monitor stationary users, this can be useful when scaling observations to the whole population for example.

The measurement sampling process is somewhat different if the aim is to estimate travel times in real-time or generate historic travel patterns, travel statistics and OD flows.

For real-time travel time estimation there is a need to continuously filter out users that are not related to the transportation network, e.g. stationary users and pedestrians. This step can be performed in combination with the traffic state calculation. Stationary users can be filtered out by ignoring terminals that has a speed, as determined by e.g. handovers, below for example $6 \mathrm{~km} / \mathrm{h}$ [59]. This means that terminals not moving fast enough will never be considered in the traffic state estimation. A similar approach is described in [28], with the difference that outliers are filtered in relation to the average speed in the previous time period. An interesting problem arises during congestion when vehicles are travelling at a lower speed than the chosen threshold. However, a potential way of reducing effects from this is to consider terminals that recently have been registered for a higher speed as valid probes, although they currently might be travelling at a lower speed than the threshold.

In order to estimate travel times, two accurate locations with suitable separation are needed. These locations are straightforward using active monitoring, since it can be the periodically collected position estimates. In passive monitoring a lot more information is typically available from the active terminals, and we can choose to estimate the position of the terminals at locations that are suitable from both a travel time 
and positioning accuracy point of view. As illustrated in Figure 6, the location can be estimated using handovers or by analysing measurement reports and defining proprietary location triggers. The potential gain in using proprietary triggers is that the handovers are not optimised to estimate positions, but instead optimising cellular network performance. The handovers can for example be a function of network load or interference, which can give a bias to the predicted handover location. The drawback of using a proprietary location trigger is that a lot more processing is needed. The measurement sampling for travel time estimation is discussed in detail in Paper IV of this thesis.

For historic travel patterns, travel statistics and OD flows the measurement sampling is often referred to as trip detection or trip generation. A number of different trip detection methods is proposed in the literature, see e.g. [59, 60]. This topic is further discussed in Paper VI of this thesis.

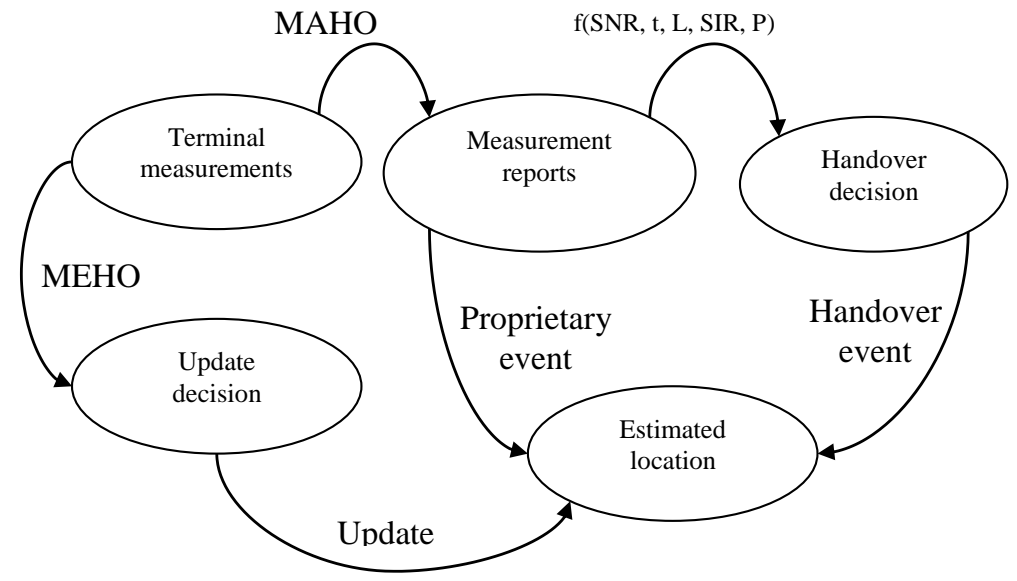

$$
\begin{array}{ll}
\text { SNR }=\text { Signal-to-Noise Ratio } & \mathrm{t}=\text { time } \quad \mathrm{L}=\text { Network Load } \\
\text { SIR = Signal-to-Interference Ratio } & \mathrm{P}=\text { max transmitted BTS power }
\end{array}
$$

Figure 6. Different approaches to position estimation using measurement reports for travel time estimation.

\section{Travel Mode and Route Classification}

Since the location data from the cellular network is relatively coarse, mode and route classification is a both challenging and important step of the process. Naïve map matching or route classification methods are not likely to work well, instead more advanced methods incorporating motion models, transportation network structure and assumptions on travel behaviour are needed. 
Map matching for active monitoring systems is described in detail in e.g. [33]. More advanced methods for route classification based on sparsely sampled billing data is discussed further in Paper VI and described in more detail in e.g. [61]. When passive monitoring is used, the sampling rate (from measurement reports) will typically be much higher and route classification methods for more dense sampling are presented in e.g. [62, 63]. Route classification for densely sampled measurement reports is further discussed in Paper II and Paper IV of the thesis. The tracking of cell phones using measurement reports in combination with Markov Models and Kalman filtering are discussed further in [62, 64]. Paper IV also discusses tracking of densely sampled measurements reports in more detail.

Although being a priority area for the use of cellular network signalling data for transport analytics, the mode classification problem has obtained little attention in literature. For travel statistics and OD estimation, it is in many cases very suitable to get the data classified per mode. For travel time estimation, buses and taxis can bias the estimations if they travel in a separate lane. Also motorcycles, cycles and even trains can be a problem in some cases. Taxis, motorcycles and cycles are very difficult to detect unless we have many samples in a time interval. In [65] a promising method to classify buses and possibly also trains using their timetables is described.

An important feature of mobility data from cellular networks is that it is possible to get observations from all travel modes, and in some cases it is very interesting to get the total travel demand even without getting it separated per travel mode.

The mode classification problem is very similar to the route classification problem separate for only road networks. The difference is that we need transport network representations for all traffic modes, and the classification problem is limited to determining which of the best routes for the different modes that is most likely. Successful route classification models are likely to perform well also on the mode classification problem.

\section{Traffic State Estimation}

The method for traffic state estimation based on mobility data from cellular networks depends on the type of traffic state or statistic that is to be calculated.

For OD estimation, travel statistics and general travel patterns, the output of the mode and route classification phase is trips classified into different modes with a most likely route included. This data can be aggregated to travel statistics like travel length distribution or number of trips per day and user. For OD estimation the trips can be aggregated for each OD pair and aggregate route choices can also be calculated for each OD pair. In order to calculate absolute flows, the sample from the subscribers of the mobile operator needs to be scaled to the whole population. The scaling can for example be based on census data, dedicated flow measurements from sen- 
sors or operator penetration estimates. This area is still very unexplored in literature and most of the results so far are relative metrics. Earlier work on OD-matrix and traffic flow estimation can be found in e.g. [66, 67]. More recent work can be found in e.g. $[36,68]$. OD estimation, and other travel flow estimates as well as route choice are further discussed in Paper VI of the thesis.

The early work on travel time estimation based on cellular network signalling data included only a limited number of state estimation models. The traffic state is in [27] estimated using handovers and both a first-order model including average speed and a second-order model also incorporating estimated traffic flow. The estimated state is then filtered using a particle filter. In [28] handovers and a first-order model in combination with a Kalman filter is used to estimate average speed. A more recent and very thorough analysis can be found in [35]. More advanced methods for travel time estimation based on traffic model assimilation and sensor fusion is further discussed in Chapter 6 as well as in Paper V of the thesis.

Incident detection can be carried out using travel times, traffic flow, or a combination of the two estimates. However, as first described in [37], there is also a strong correlation between congestion and the number of phone calls, since people tend to start making phone calls when entering a queue. 


\section{Chapter 5 Spatiotemporal Characteristics}

The quality of road traffic state estimation based on cellular networks is dependent on a number of aspects related to the geographic location. The potential quality depends on the cellular network structure and configuration as well as the road network structure together with traffic characteristics of both the cellular and road network. The actual performance will also be affected by the implementation of the positioning, tracking and route classification methods.

The structure of the cellular network determines the available data for position estimation. Smaller cells give generally less ambiguity in position estimations and also more handover locations that can be used for travel time estimation. The route classification is also easier to perform with a higher density of cells. A configuration made by the mobile operator is how to design the registration areas, i.e. how to group the cells into URA, RA and LA, and this will also affect the available location data.

Correspondingly, the structure of the road network will also affect the challenges in extracting useful information. One of the major challenges today is to estimate high quality travel times using cellular networks in urban environments. The challenge using this kind of system in an urban environment lies mainly in the large number of non-vehicle terminals and possible routes. Furthermore, the mean speed of vehicle terminals is not much higher than non-vehicle terminals, especially in the case of congestion. The travel times are also exposed to large variations due to waiting times in signalized intersections. An interesting approach to reduce the effects of large variations in urban environments is described in [31], where the probability of stopping 
on a link due to a traffic signal is used when decomposing route travel times into link travel times. Methods for route classification and travel time estimation in urban environments is further discussed in paper IV.

The traffic characteristics of the cellular network are naturally important for the estimation quality, as well as the road traffic characteristics, which are affecting indirectly, i.e. few cars means few cell phones and hence few measurements. This is not a major issue since traffic related problems are typically limited when the traffic flow is low. The number of observations from the cellular network is however a key indicator of the quality. Since the measurements are relatively noisy, it is important to have several samples in a time period in order to achieve high quality measurements. The relation between number of samples and estimation quality is discussed in detail in [30].

\section{Spatial Resolution}

The spatial resolution of mobility measurements from cellular network signalling data depends on the type of data collected, i.e. billing data, location updates, handovers, measurement reports or dedicated positioning data (see Chapter 2). It also depends on the type of cellular network, e.g. GSM, UMTS or LTE as well as the configuration of the network. The spatial resolution of handovers are discussed further in Paper III and the spatial resolution of measurement reports are described in more detail in Paper I and Paper IV of the thesis.

For several types of signalling data we only have information about the connected cell id, i.e. no measurement reports or dedicated positioning data is available. For some of this signalling data, e.g. handovers, cell updates or location area updates, the event is registered when a cell change is made, which makes it more likely to occur on the cell border. For others, the event is not related to a cell change, e.g. billing data or periodic updates, and the location data corresponds to the cell coverage. When only cell id is available, the base station density and antenna configuration is very important for the spatial resolution, since it will determine the average cell size. However, there are several ways to describe the cell id data in terms of location data. The simplest way of representing cell id data is to use the location of the antenna. To model the large uncertainty of the cell id observation an estimated coverage can also be used. In some cases a hexagon representation is used, but the most common way of representing cell coverage is to generate Voronoi zones based on the antenna locations, see example in Figure 7. However, Voronoi representation can give really bad representations in the case of hierarchical cell structures with combinations of micro and macro cells. A better approximation of cell coverage is given by propagation models using information about antenna direction, transmission power and topography. These models are typically maintained by the mobile operator for the purpose of 
radio planning and optimisation, an example is shown in Figure 8. In reality the coverage area for a cell can be very complex, see example in Figure 9, and participatory sensing methods to support cell coverage prediction can be very useful.

All idle terminals, i.e. terminals that are switched on but not actively used, report their location as soon as they enter a new LA, RA, URA or TA, depending on type of network. These registration areas are typically designed to minimize signalling traffic in the network [70] and the configuration can affect the amount and quality of the data that can be extracted from the cellular network. Figure 10 gives an example of spatial resolution of location areas for a GSM network in Sweden.

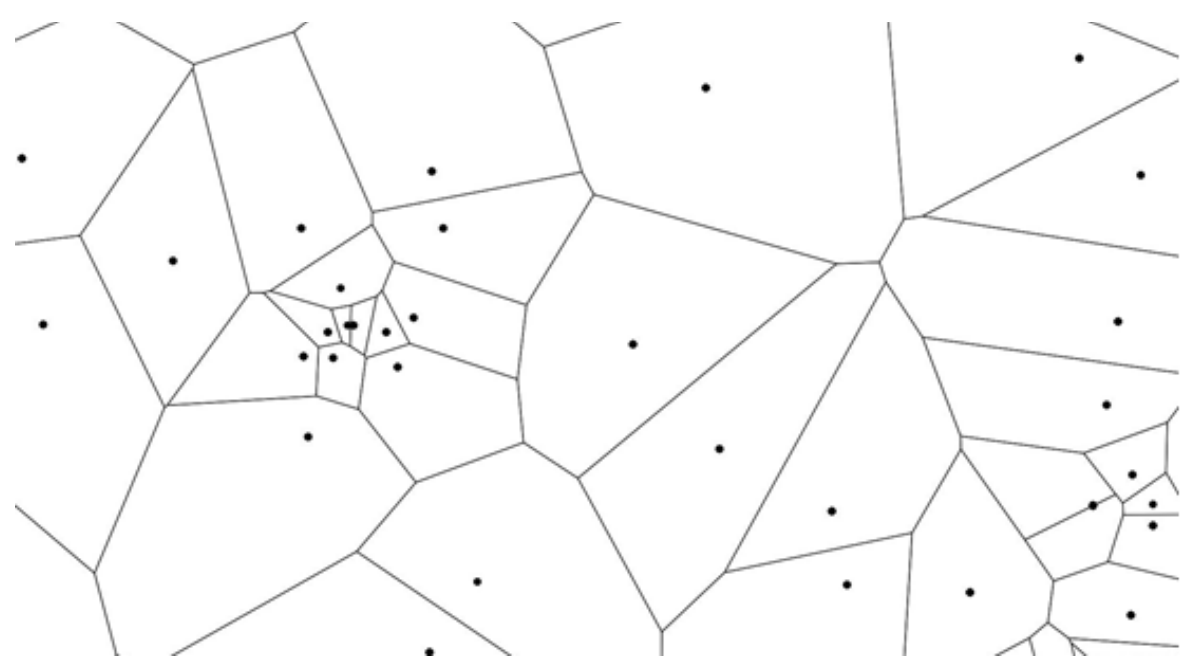

Figure 7. Example of Voronoi representation of cells where the black dots are antenna locations. 


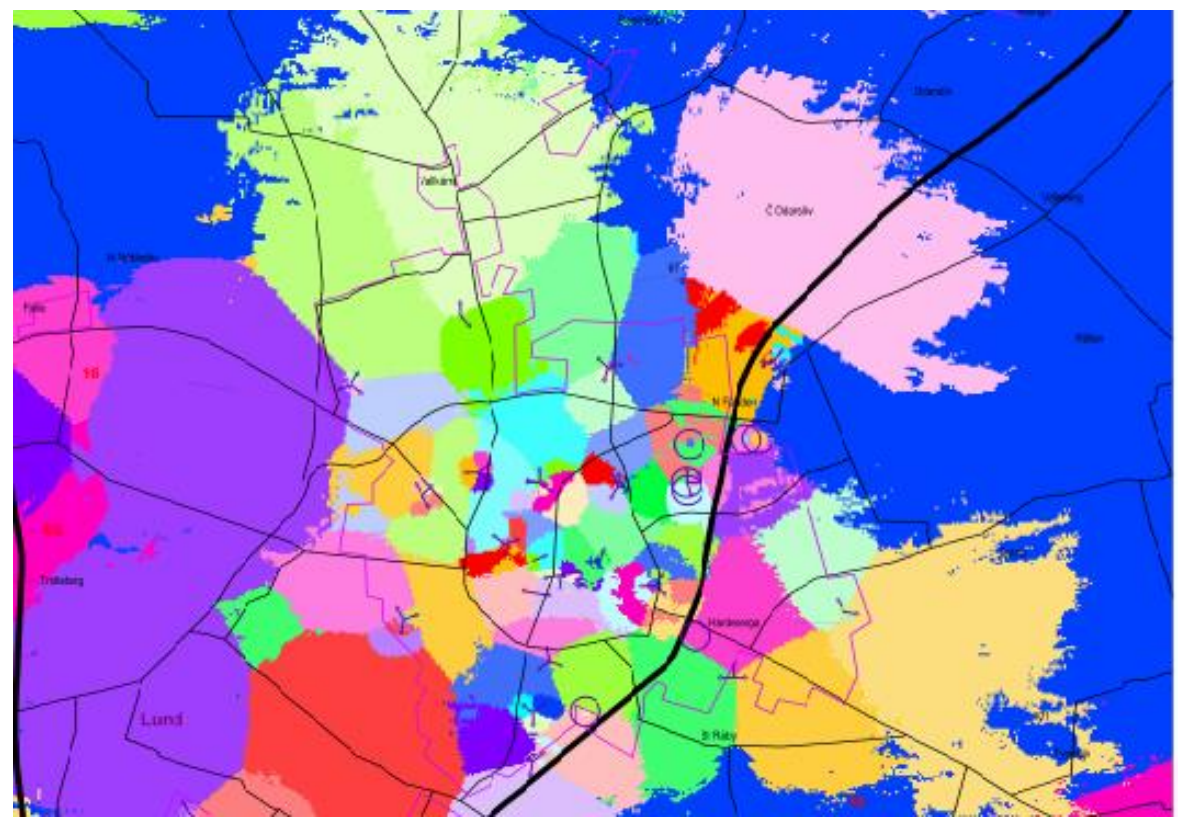

Figure 8. Example of GSM cell coverage prediction based on a propagation model in an operators network planning tool.

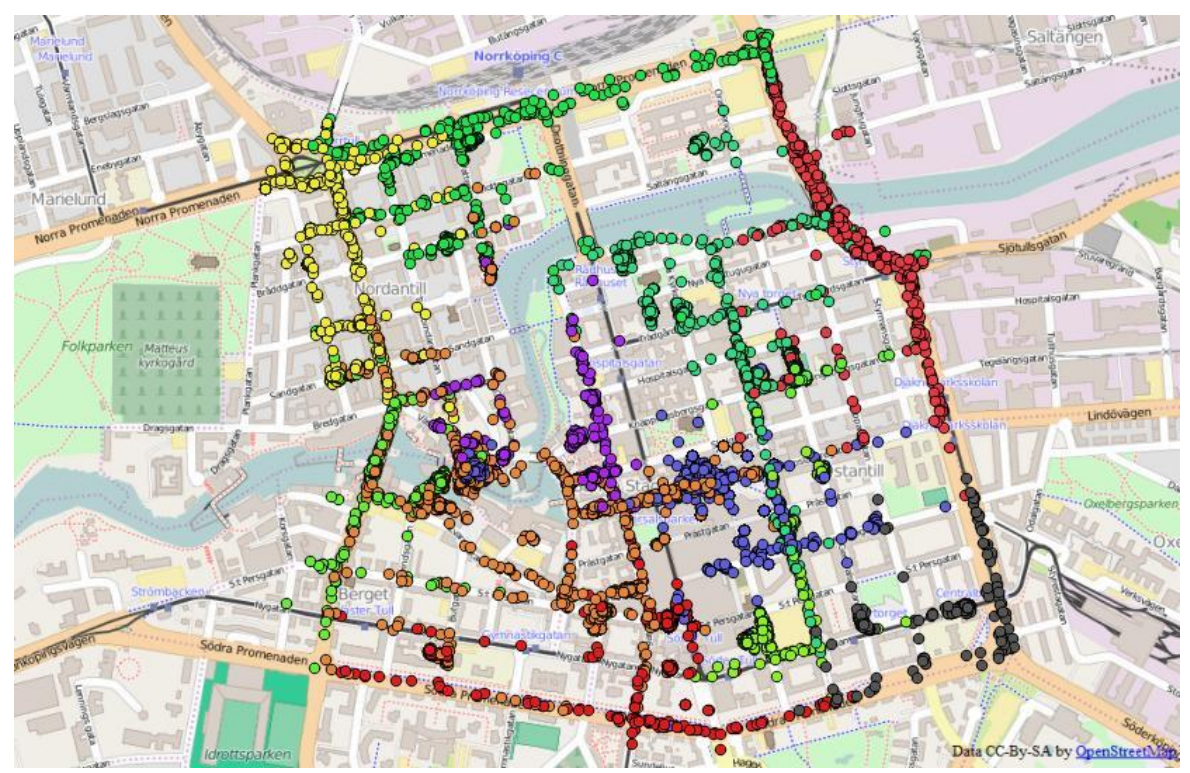

Figure 9. Example of overlapping cells in the city of Norrköping, Sweden. Different colours indicate coverage of different cells. 


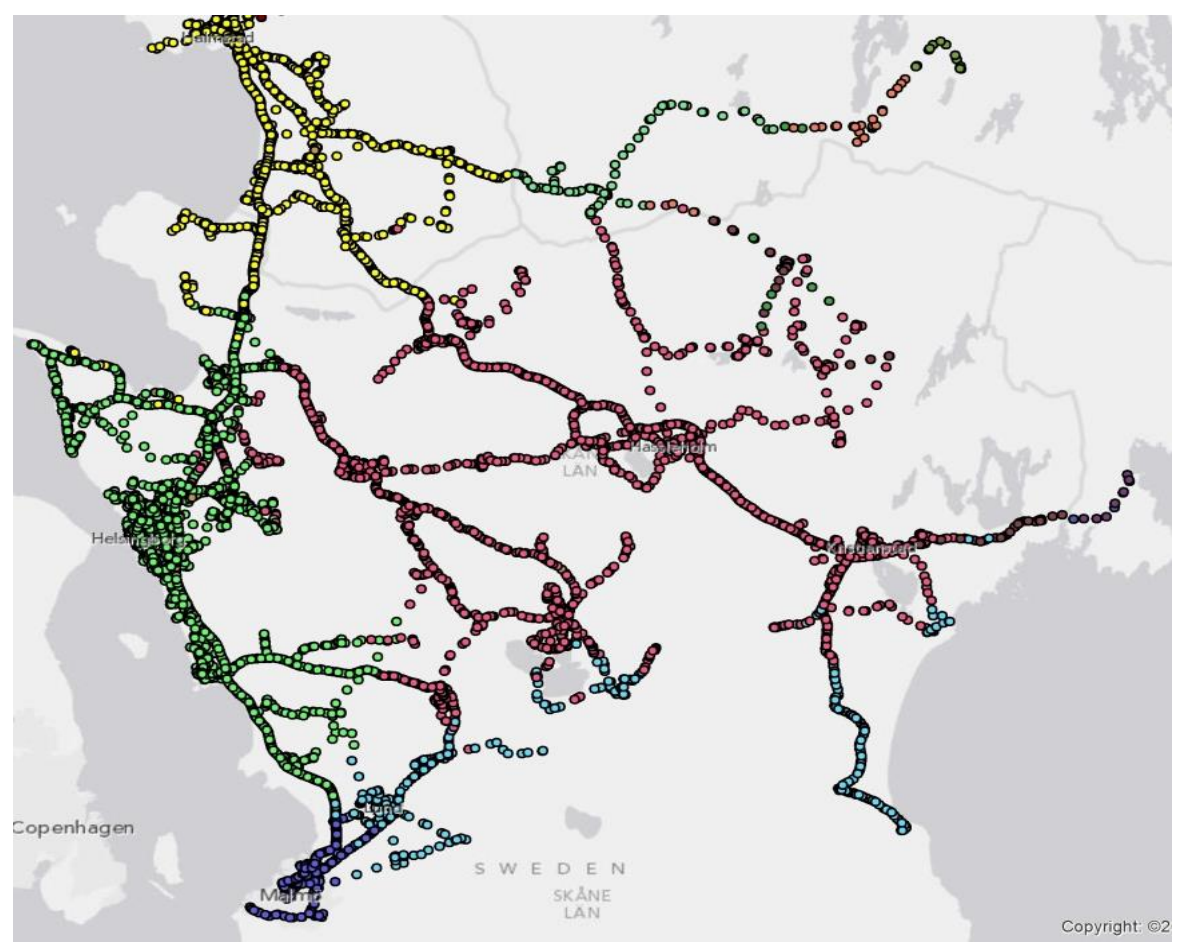

Figure 10. Example of Location Areas for GSM in south of Sweden. Different colours indicate different location areas.

\section{Temporal Resolution}

The temporal resolution of mobility measurements based on cellular network signalling data can vary dramatically depending on which type of data that is used. The temporal resolution of billing data can be in the order of hours (whenever a telephone call and SMS is initiated), whereas the temporal resolution of measurement reports can be in the order of sub seconds. This fact is very confusing for different actors that want to make use of cellular network signalling data and understand the potential for transport analytics, especially many publications on the topic to date uses billing data with relatively sparse sampling.

The mobile operator's platform for extracting data in combination with the type of cellular network that is used will determine the temporal resolution of the data. It is not clear from literature what temporal resolution to expect from modern data collection platforms, it is a combination of how often the mobile terminal is transmitting and receiving and which type of signalling data that is extracted.

If billing data is used, the expected temporal resolution depends on if packet switched data is logged or not. If only calls and SMS are logged the temporal resolution is typically in the order of hours, see for example Paper VI, and if also packet switched data is logged the temporal resolution is somewhat improved. 
A strategy to reduce the number of data collection probes is to collect data from the core network only. For terminals that are active we can expect to have all cell changes, but no measurement reports, available in the core network, and the temporal resolution will in that case depend highly on the cell size and the mobility of the terminal.

With more advanced platforms for data collection and improved computational power as well as disk capacity of the platforms, it is likely that in the near future more dense data will be available based on measurement reports from the radio network. 


\section{Chapter 6 Sensor Fusion and Model Assimilation}

Filtering, fusion and assimilation are all referring to the process of improving the accuracy of a traffic state estimate by interpolation and removal of noise and bias in measurements. The main difference between the different concepts relates to the core methodology of improving the estimate. In plain filtering, there is typically only one modality of measurement included. In fusion, the focus is to combine measurements of different modalities and in assimilation the focus is to combine measurements with the output of a mathematical model. However, whereas assimilation can include multiple measurement types, fusion typically includes a model for the system evolution. In general, to turn the raw traffic data into a state estimate, a number of steps needs to be performed:

- Step 1. Removing outliers and erroneous measurements, which could induce large errors and biases in the estimate.

- Step 2. Filling gaps in data, since malfunctioning sensors and the removal of outliers will generate gaps. These gaps must be filled in order to have complete coherent series of observations.

- Step 3. Fusing measurements from different sources, to extract the richest homogeneous information from the heterogeneous data available.

- Step 4. Combining the measurements with a system or process model. 
In some literature, especially in the area of weather predictions and hydrology, Step 4 is referred to as assimilation [71]. For traffic state estimation, typically Step 1 and 2 are jointly implemented as a preprocessing step and Step 3 and 4 are implemented as a joint fusion and assimilation step. In the first step, knowledge of the physical process that is observed and the sensor that produces the measurements can be used to remove outliers and obviously faulty measurements. In the second step the outliers are replaced with reasonable values. Although both fusion and more complex process models can be used in this step, often very basic system models are used separately for sensors with different modality. In Step 3, sensors with different modality are fused together to improve the estimate. The different modalities require models for translation between them, these are often referred to as measurement models, and an example can be the relationship between flow and density, i.e. the fundamental diagram of traffic. Different sensors are also separated in space and their observations are separated in time, which requires models for the evolution of the state in both the spatial and temporal domain.

There are two types of models that are of main interest for assimilation when cellular network signalling data is used for road traffic state estimation. Firstly, the noisy location data can be improved significantly by assimilation with a motion or mobility model of the mobile devices. A good overview of motion models for target tracking is given in [72]. Once the raw trajectory data is filtered and aggregated for many devices it is useful to assimilate the data with a traffic model. There are many types of traffic models available for estimation and prediction of traffic. Static traffic modelling means that traffic variables are modeled only for one time interval, e.g. the daily peak hour, whereas dynamic traffic models includes the state propagation in time. In macroscopic traffic models the traffic conditions are described by aggregated measures (e.g. flow, density, and speed). Examples include the Lighthill Witham Richards (LWR) model [73], and its discretized version, the cell transmission model (CTM) [74]. Microscopic traffic models includes the location, speed and acceleration of each vehicle and models the interaction between the vehicles. Mesoscopic traffic models is a combination that can have both macro- and microscopic components. For traffic assimilation, dynamic macroscopic models are mainly used, due to the possibility of modeling time evolution and being computational efficient.

A very common method for both fusion and assimilation is the Kalman filter [75, 76]. For a more in depth description of Kalman filtering, and its extensions, in traffic management and control, the reader is referred to [77, 78]. For use in target tracking, the reader is referred to e.g. [72]. For nonlinear state evolutions, non-linear measurement models or non-Gaussian noise, other filters are better suited, common examples include extended Kalman filtering [79], particle filtering [80] and ensemble Kalman filtering [71]. 
The models applied in this thesis are a motion model for tracking of a vehicle and a traffic model for prediction of the road traffic state. Paper IV includes a particle filter with data-driven motion model for improving noisy location data based on cellular network measurement reports. The particle filter is used handle the multi-modal posterior distribution that occurs when tracking vehicles on a road network. Paper V combines different types of traffic measurements with a cell transmission model using ensemble Kalman filtering for travel time estimation. The ensemble Kalman filter is chosen to cope with the nonlinear traffic model as well as the relatively large state vector. 



\section{Chapter 7 The Thesis}

The aim of the thesis is to evaluate the potential in using cellular network signalling data applied to transport analytics. Transport analytics is here interpreted as the discovery, interpretation, and communication of meaningful patterns in transportrelated data and includes data-driven methods for estimation, prediction, management, control and planning of transportation networks. The work is focused on developing methods for processing the noisy location data available in cellular networks to support state estimation and planning of road traffic networks.

\section{Objectives}

With the aim to evaluate the potential in using cellular network signalling data for the application of transport analytics the following research questions are stated:

- Which type of signalling data available in cellular networks is relevant for transport applications?

- What is the spatiotemporal resolution of the relevant signalling data and which transport applications is it suitable for?

- How should a processing pipeline that turns cellular network signalling data to location data useful for transport applications be designed?

- How should the noisy location data based on measurement reports be processed to support travel time estimation?

- How should the spatiotemporally sparse billing data be processed to support calculation of mobility metrics that are of interest in transport planning?

- How can cellular network data efficiently be combined with other sensor data and traffic models? 
To answer these questions, different types of data from the cellular network is collected and analysed. New methods for processing the cellular network data for transport applications are also proposed and evaluated.

\section{Research Method}

There are a number of different methods available to evaluate the potential of cellular network signalling data for transport applications. We have focused on analysing the spatiotemporal resolution of the underlying signalling data, which can be used to quantitatively evaluate how this data can be used for several different types of trafficrelated metrics, e.g. travel times, route choice or OD flows. For quantitative analysis of the spatiotemporal resolution of the signalling data, we can use empirical experiments, analytical models or simulation models. The major disadvantage of most analytical models are the assumptions and simplifications of the analysed system that needs to be made. Simulation models typically allow modeling of much more complex systems than analytical models, the drawback, on the other hand, is the time required to build, verify, calibrate and validate the model as well as evaluating different scenarios. With this in mind, the method of choice is empirical experiments where the signalling data from the cellular network is collected in different ways and analysed using statistical methods. The drawback with experiments is that it is difficult to evaluate future changes of the system and more challenging to generalize the results.

For the location estimation based on the underlying signalling data, we chose to use a classification method instead of regression or geometric methods. The reason for this is that classification methods often outperforms geometric methods when received signal strengths are used as input, especially if empirical data is used to create the radio map. To further improve the location accuracy a particle filter combined with a data-driven motion model based on historic GPS-data is used.

For fusion and assimilation of travel time observations with point speed observations and a dynamic macroscopic traffic model the ensemble Kalman filter is used. Macroscopic traffic models do not allow modelling of direct interactions between vehicles, but has the advantage of being easier to calibrate and also more computational efficient, which enables real-time traffic state estimation and prediction.

The empirical data from the cellular network is collected in different ways using different types of methods. In paper II and paper III data is collected using the monitoring tool TEMS Investigation which in combination with a special mobile terminal enables logging of all signalling data that is generated between the mobile terminal and the cellular network. In paper I and IV cell id and received signal strengths of main and neighbouring cells are collected through the Android API of standard smartphones. In paper III the same data is collected but instead through the operating 
system of simpler GPS and GPRS devices. In paper VI billing data from the D4D challenge provided by the mobile operator Orange is used for the analysis.

\section{Contributions}

The thesis makes the following scientific contributions:

- Structures and describes the data related to location and mobility estimation available in cellular networks.

- Explores and describes the characteristics of relevant cellular network signalling data in the context of state estimation of transportation networks.

- Presents a new framework for processing cellular network signalling data for the purpose of travel time estimation.

- Identifies and gives insight to the route classification problem in the context of travel time estimations based on noisy sensor data.

- Demonstrates that the route classification problem can be solved efficiently for highway environments using measurement reports and basic classification algorithms.

- Develops and evaluates a novel method for integrated travel time sampling and route classification for travel time estimation based on measurement reports from the cellular network.

- Shows the potential in using particle filtering and integrity monitoring in the context of improving cellular network location estimates for vehicle tracking.

- Develops and implements a novel method for fusion of travel time measurements with point speed measurements using a first-order macroscopic traffic model. The method can run in real-time for a large-scale traffic network.

- Presents a framework for processing cellular network billing data with sparse spatiotemporal resolution for the purpose of travel demand estimation.

- Gives insight into the effect of different trip generation algorithms for OD estimation based on cellular network billing data. 


\section{Paper Summary}

The thesis consists of six papers. Paper I and Paper II focus on location estimation. Paper III focuses on route classification and Paper IV includes combined route classification and sampling for travel time estimation. Paper $\mathrm{V}$ includes more advanced methods for travel time estimation and finally paper VI focuses on mobility patterns for urban and traffic planning.

- Paper I: Gundlegård D, Karlsson J M, The Smartphone as Enabler for Road Traffic Information Based on Cellular Network Signalling, published in Proceedings of 16th International IEEE Conference on Intelligent Transportation Systems (ITSC), 6-9 October 2013, The Hague, Netherlands, IEEE, 2013

This paper evaluates the possibility of using GPS-enabled smartphones for building a radio map using participatory sensing. Furthermore, the accuracy of a cellular location system based on that radio map is assessed and related to road traffic information based on cellular network signalling. The evaluation is performed based on combined GPS and received signal strength data collected using a dedicated Android application.

The thesis author is the main author of the paper and has been responsible for research planning, data collection, method development, analysis and paper writing. The co-author has given feedback on the content and structure of the paper.

- Paper II: Gundlegård D, Karlsson J M, Handover Location Accuracy for Travel Time Estimation in GSM and UMTS, published in IET Intelligent Transport Systems, Vol. 3, Issue 1, pp. 87-94, 2009.

In this paper a spatial analysis of handover events is performed. The analysis focuses on determining the location accuracy characteristics of the events and how it affects travel time estimation based on handovers as well as potential and limitations in GSM and UMTS networks. The data is collected using a tool for cellular network analysis which includes hardware and software for extracting all signalling data generated between a mobile device and the network.

The thesis author is the main author of the paper and has been responsible for research planning, data collection, method development, analysis and paper writing. The co-author has given feedback on the content and structure of the paper. 
- Paper III: Gundlegård D, Karlsson J M, Route Classification in Travel Time Estimation Based on Cellular Network Signaling, published in Proceedings of 12th International IEEE Conference on Intelligent Transport Systems (ITSC), St. Louis, October 3-7 2009, pp. 474-479, IEEE, 2009

This paper defines and analyses the route classification problem that occurs when estimating travel times based on handover events from the cellular network. The analysis is performed based on combined GPS and received signal strength measurements from GPRS devices located in vehicles.

The thesis author is the main author of the paper and has been responsible for research planning, data collection, method development, analysis and paper writing. The co-author has given feedback on the content and structure of the paper.

- Paper IV: Gundlegård D, Karlsson J M, Integrated Tracking and Route Classification for Travel Time Estimation based on Cellular Network Data, submitted to Transportation Research Part C - Emerging Technologies.

The aim of the paper is to investigate the potential in using detailed cellular network signalling data for the purpose of travel time estimation and route classification. The paper proposes a processing pipeline for estimating travel times and route classification based on cell id and received signal strength measurements from the cellular network. The processing pipeline is evaluated using combined GPS and received signal strength measurements collected using a dedicated Android application.

The thesis author is the main author of the paper and has been responsible for research planning, data collection, method development, analysis and paper writing. The co-author has given feedback on the content and structure of the paper.

- Paper V: Gundlegård D, Allström A, Bayen A, Bergfeldt E, Ringdahl R, Travel Time and Point Speed Fusion Based on a Macroscopic Traffic Model and Non-linear Filtering, published in Proceedings of 18th International IEEE Conference on Intelligent Transportation Systems (ITSC), 15-18 September 2015, Las Palmas, Spain, IEEE, 2015.

The aim of this paper is to use a macroscopic traffic model together with a non-linear filtering framework for efficient fusion of point speed and travel times observations. The method is evaluated using GPS probe data from taxis and radar sensors observing point speed and flow.

The thesis author is the main author of the paper and has been responsible for the overall research planning, data collection, method development, 
analysis and paper writing. The co-authors have given feedback of the content and structure of the paper. The co-authors have also been responsible for documenting previous work as well as performing selected experiments.

- Paper VI: Gundlegård D, Rydergren C, Breyer N and Rajna B, Travel Demand Estimation and Network Assignment Based on Cellular Network Data, published in Computer Communications, vol. 95, pp. 29-42, 2016.

The aim of this paper is to outline the potential of mobile cellular network data with focus on Call Detail Records (CDR) in the context of mobility, transport and transport infrastructure analysis. The paper includes how mobile phone data can be processed to enter in traditional transportation analysis models and a modified methodology for handling the different steps in travel demand estimation and network assignment.

The thesis author is the main author of the paper and has been responsible for the overall research planning, method development, analysis and paper writing. The two data sets used in the paper is provided by the mobile operator Orange in the two research challenges; Data for Development (D4D) -Côte d'Ivoire in 2012/2013 and D4D -Senegal in 2014/2015. The thesis author has been responsible for managing the data as well as the submission of both contributions to the challenges. The article writing process has been a joint work between the authors. The co-authors have contributed with development of selected trip detection and routing algorithms in collaboration with the thesis author.

The thesis is an extension of the author's Licentiate thesis:

- Gundlegård D, Generating Road Traffic Information Based on Cellular Network Signalling. Linköping: Linköping University Electronic Press; 2013. Linköping Studies in Science and Technology. Thesis, 1577.

A number of related publications have also been published, but are not included in this thesis:

- Gundlegård D, Karlsson, J M, Generating Road Traffic Information From Cellular Networks - New possibilities in UMTS. In: Proceedings of 6th International Conference on ITS Telecommunications, 2006, 1128-1133, 2006, IEEE 
- Allström A, Gundlegård D, Rydergren C, Evaluation of travel time estimation based on LWR-v and CTM-v: A case study in Stockholm. In: 14th International IEEE Conference on Intelligent Transportation Systems (ITSC 2012). IEEE conference proceedings; 2012.

- Gundlegård D, Akram A, Fowler S, Ahmad H, Cellular Positioning Using Fingerprinting Based on Observed Time Differences. In: IEEE 4th International Conference on Smart Communications in Network Technologies (SaCoNet). IEEE conference proceedings; 2013.

- Gundlegård D, et. al., Mobility Modeling for Transport Efficiency-Analysis of Travel Characteristics Based on Mobile Phone Data. In: Third conference on Analysis of Mobile Phone Datasets (MIT NetMob 2013), D4D Challenge, Boston, MA, USA, May 2013.

- Gundlegård D, Rydergren C, Barcelo J, Dokoohaki N, Görnerup O and Hess A, Travel Demand Analysis With Differentially Private Releases. In: Fourth conference on Analysis of Mobile Phone Datasets (MIT NetMob 2015), D4D Challenge, Boston, MA, USA, April 2015.

- Gundlegård D, Karlsson J M, Road Traffic Estimation using Cellular Network Signalling in Intelligent Transportation Systems. In: Wireless technologies in Intelligent Transportation Systems, Hauppauge, NY: Nova Science Publishers; 2009, Transportation Issues, Policies and R\&D

- Allström A, Bayen A M, Fransson M, Gundlegård D, Patire A D, Rydergren C and Sandin M, Calibration Framework based on Bluetooth Sensors for Traffic State Estimation Using a Velocity based Cell Transmission Model. In: 17th Meeting of the EURO Working Group on Transportation, EWGT2014, 2-4 July 2014, Sevilla, Spain. Elsevier; Transportation Research Procedia. 2014; 3:972-981.

- Allström A, Barceló J, Ekström J, Grumert E, Gundlegård D and Rydergren C, Traffic management for smart cities. In: Designing, Developing, and Facilitating Smart Cities : Urban Design to IoT Solutions. Part III, Switzerland, 2016, pp. 211-240.

- Allström A, Ekström J, Gundlegård D, Ringdahl R, Rydergren C, Bayen A M and Patire A D, Hybrid Approach for Short-Term Traffic State and Travel Time Prediction on Highways. In: Transportation Research Record, vol. 2554, pp. 60-68, 2016.

- Breyer N, Gundlegård D, Rydergren C and Bäckman J, Trip extraction for Traffic Analysis Using Cellular Network Data. In: Proceedings of 2017 5th IEEE International Conference on Models and Technologies for Intelligent Transportation Systems (MT-ITS). 
- Breyer N, Rydergren, C and Gundlegård D, Cellpath Routing and Route Traffic Flow Estimation Based on Cellular Network Data. In: The Journal of Urban Technology, 1-20. https://doi.org/10.1080/10630732.2017.13869

\section{Conclusions and Future Research}

The results from this thesis show that several types of data are suitable for travel time estimation, this includes handovers, measurement reports as well as billing data. The accuracy and spatial resolution of the travel time and in what environment we can expect to get useful results, varies significantly between the different data types though. We have shown that handovers and measurement reports can be used for travel time estimation in highway environments and that billing data can be used to get rough travel times for long distance trips. We have also shown that basic classification methods can be used to solve the route classification problem based on cellular network measurement reports in highway environments.

For travel time estimation and route classification based on cellular network measurement reports in urban environmoments, we have shown that more advanced sampling, filtering and classification methods can be used to get useful results.

Combining relatively sparse sampled travel times, as expected from cellular network data, with a first order macroscopic traffic model and local flow and speed observations using an Ensemble Kalman filter can be used to remove travel time outliers and also reduce effects from poor calibration of the model.

For mobility patterns with lower requirements on spatial and temporal resolution, like time sliced OD matrices or travel statistics, it is possible to use both measurement reports, location updates and billing data to enable useful input to decisions on urban or traffic planning.

Cellular network signalling data is a huge and relatively unexplored data source for transport applications and future work includes a large number of interesting research questions. The future work that is most important related to this thesis, however, is related to $4 G$ and $5 G$ networks, mode choice and large scale validation. This thesis is focused on $2 \mathrm{G}$ and $3 \mathrm{G}$ network data and the data in $4 \mathrm{G}$ and $5 \mathrm{G}$ networks have different characteristics. With a higher base station density and higher data rates it is expected that the spatiotemporal resolution of the data will be improved, the question is how much it will be improved and if that enables also new type of applications within transport. For a data source that enables monitoring of all transportation modes, it is very interesting to be able to observe each travel mode separately. Adaption of the route classification methods described in this thesis to also include mode choice, is hence a very interesting topic for the near future. When more and better datasets with cellular network signalling data becomes available, it is also more 
likely that the data overlaps with other traffic and mobility sensors so that large scale validation and benchmarking of the data source can be made.

Based on the spatiotemporal resolution and coverage of cellular network data together with the ability to follow subscribers over longer periods of time, we should expect that efficient use of this data source will fundamentally change how we can understand human mobility, travel patterns and transportation network usage the coming years. 


\section{References}

[1] University of Maryland Transportation Studies Center (1997). Final Evaluation Report for the CAPITAL-ITS Operational Test and Demonstration Program. University of Maryland, College Park.

[2] Y.-A. de Montjoye, Z. Smoreda, R. Trinquart, C. Ziemlicki, V.D. Blondel (2014), D4D-Senegal: The Second Mobile Phone Data for Development Challenge, CoRR.

[3] V.D. Blondel, N. de Cordes, A. Decuyper, P. Deville, J. Raguenez, S. Zbigniew (2013), Mobile Phone Data for Development, Analysis of Mobile Phone Datasets for the Development of Ivory Coast (D4D Book), http://perso.uclouvain.be/vincent.blondel/netmob/2013/D4D-book.pdf.

[4] D. Naboulsi, M. Fiore, S. Ribot, and R. Stanica (2016), Large-Scale Mobile Traffic Analysis: A survey. IEEE Communications Surveys \& Tutorials, vol. 18, no. 1, pp. 124-161.

[5] D. Gundlegård and J.M. Karlsson (2009), Road Traffic Estimation using Cellular Network Signalling in Intelligent Transportation Systems. In Wireless Technologies in Intelligent Transportation Systems, Hauppauge, NY: Nova Science Publishers; Transportation Issues, Policies and R\&D

[6] A. Allström, J. Barceló, J. Ekström, E. Grumert, D. Gundlegård, and C. Rydergren (2016), Traffic Management for Smart Cities. In Designing, Developing, and Facilitating Smart Cities: Urban Design to IoT Solutions. Part III, Switzerland, pp. 211-240.

[7] 3GPP (2005). Requirements for support of radio resource management, TS 25.133, v. 7.2.0.

[8] 3GPP (2007). Radio Resource Control (RRC); Protocol Specification. TS 25.331, v. 8.0.0 
[9] 3GPP (2005). Requirements for support of radio resource management. TS 25.133, v. 7.2.0.

[10] 3GPP (2002). General Packet Radio Service (GPRS); Service description; Stage 2. TS 03.60, v. 9.7.0.

[11] 3GPP (2007). Radio Access Network; Functional stage 2 description of Location Services (LCS) in GERAN. TS 43.059, v. 8.0.0.

[12] 3GPP (2007). Stage 2 functional specification of User Equipment (UE) positioning in UTRAN. TS 25.305, v. 8.0.0.

[13] A. Küpper (2005), Location-Based Services: Fundamentals and Operation. West Sussex, Wiley.

[14] G. Heine (1999), GSM Networks: Protocols, Terminology, and Implementation. Boston, Artech House.

[15] H. Kaaranen, A. Ahtiainen, L. Laitinen, S. Naghian and V. Niemi (2001). UMTS Networks - Architecture, Mobility and Services. West Sussex, John Wiley \& Sons, Ltd.

[16] H. Holma and A. Toskala (2002), WCDMA for UMTS - Radio access For Third Generation Mobile Communications (Second Edition). West Sussex John Wiley \& Sons, Ltd.

[17] K. Hiltunen, N. Binucci and J. Bergström (2000), Comparison Between the Periodic and Event-Triggered Intra-Frequency Handover Measurement Reporting in WCDMA. Proceedings of WCNC.

[18] J. Borkowski, J. Niemelä and J. Lempiäinen (2004), Performance of CelIID+RTT Hybrid Positioning Method for UMTS Radio Networks. Proceedings of The Fifth European Wireless Conference.

[19] C. Drane and C. Rizos (1998), Positioning Systems in Intelligent Transportation Systems. Norwood, Artech House.

[20] L. Zhao and J. W. Mark (2004), Mobile Speed Estimation Based on Average Fade Slope Duration. IEEE Transactions on Communications, Vol. 52, No. 12, pp. 2066-2069

[21] M. Kirsch, \& F. Berens (2002). Mobile Speed Estimation for 3G Mobile Radio Systems Using the Normalized Autocovariance Function. International Zurich Seminar on Broadband Communications.

[22] C. Xiao, K. D. Mann and J. C. Olivier (2001), Mobile Speed Estimation for TDMA-based Hierarchical Cellular Systems. IEEE Transactions on Vehicular Technology, Vol. 50, No. 4, pp. 981-991

[23] F. Gustafsson and F. Gunnarsson (2005), Mobile Positioning Using Wireless Networks: Possibilities and Fundamental Limitations Based on Available Wireless Network Measurements. Signal Processing Magazine, IEEE vol. 22, Issue 4, pp. 41- 53. 
[24] H. Ryden, S. Modarres Razavi, F. Gunnarsson, S. M. Kim, M. Wang, Y. Blankenship, G. A. and A. Busin (2015), Baseline Performance of LTE Positioning in 3GPP 3D MIMO Indoor User Scenarios. Proceedings of International Conference on Localization and GNSS.

[25] T. Wigren (2007), Adaptive Enhanced Cell-id Fingerprinting Localization by Clustering of Precise Position Measurements. IEEE Transactions on Vehicular Technology 56, 5, pp. 3199-3209.

[26] J. Jin, Z. Qiu and B. Ran (2006), Intelligent Route-based Speed Estimation Using Timing Advance. Proceedings of IEEE ITS Conference.

[27] P. Cheng, Z. Qiu and B. Ran (2006), Particle Filter Based Traffic State Estimation Using Cell Phone Network Data. Proceedings of IEEE ITS Conference.

[28] Z. Qiu and B. Ran (2008), Kalman Filtering Applied to Network-based Cellular Probe Traffic Monitoring. Proceedings of Transport Research Board Annual Meeting.

[29] Z. Qiu, P. Cheng and B. Ran (2007). Investigate the Feasibility of Traffic Speed Estimation Using Cell Phones as Probes. International Journal of Services Operations and Informatics, Vol. 2, No. 1, pp. 53-64.

[30] Z. Qiu and B. Ran (2007), Sample Size Requirement for Cellular Probe Traffic Monitoring System. Proceedings of ITSWC.

[31] B. Hellinga, et. al, (2008), Decomposing Travel Times Measured by Probebased Traffic Monitoring Systems to Individual Road segments. Transportation Research Part C, Volume 16, Issue 6, pp. 768-782

[32] B. Hellinga, L. Fu, and H. Takada (2005), Traffic Network Condition Monitoring via Mobile Phone Location Referencing - An Emerging Opportunity, Proceedings of 6:th Transportation Specialty Conference.

[33] H. Takada, B. Hellinga, and L. Fu (2006), Link Travel Time Estimation based on Mobile Phone Location Tracking. Proceedings of ITSWC.

[34] N. Caceres, L. M. Romero, F. G. Benitez and J. M. D. Castillo (2012), Traffic Flow Estimation Models Using Cellular Phone Data. IEEE Transactions on ITS, vol. 13, no. 3, pp. 1430-1441.

[35] A. Janecek, D. Valerio, K. A. Hummel, F. Ricciato, and H. Hlavacs, The Cellular Network as a sensor: From Mobile Phone Data to Real-time Road Traffic Monitoring. IEEE Transactions on ITS, Volume 16, Issue: 5, pp. 25512572.

[36] F. Calabrese, M. Colonna, P. Lovisolo, D. Parata and C. Ratti (2011), Realtime Urban Monitoring Using Cell Phones: A Case Study in Rome. IEEE Transactions on ITS, vol. 12, no. 1, pp. 141-151. 
[37] Y. Yim (2003), The State of Cellular Probes. California PATH Research Report.

[38] G. Rose (2004), Mobile Phones as Traffic Probes. Proceedings of Conference of Australian Institutes of Transport Research.

[39] P. Sauret (2003), Pilot Project for Travel Time Measurements with Mobile Phones in Spain. 10 ${ }^{\text {th }}$ ITS World Congress.

[40] T. Karhumäki (2002), The Utilisation of GSM-Network in Travel Time Monitoring. ITS Workshop on Road Monitoring.

[41] W.V. Subbarao, et. al. (2007), Travel Time Estimation using Cell Phones (TTECP) for Highways and Roadways. Final report prepared for Florida Department of Transportation.

[42] Virginia Transportation Research Council (2005). Probe-based Traffic Monitoring State-of-the-Practice Report, NCHRP 70-01.

[43] B. Hellinga and P. Izadpanah (2007), An Opportunity Assessment of Wireless Monitoring of Network-Wied Road Traffic Conditions. Final report prepared for Ministry of Transportation of Ontario.

[44] J.L. Ygnace and C. Drane (2001), Cellular Telecommunication and Transportation Convergence. Proceedings of IEEE Intelligent Transportation Systems Conference.

[45] M. Fontaine and B. Smith (2004). Impact of System Parameters on the Accuracy of Wireless Location Technology-based Traffic Monitoring System. Proceedings of IEEE Intelligent Transportation Systems Conference.

[46] R. Cayford and V. Johnsson (2003), Operational Parameters Affecting the Use of Anonymous Cell Phone Tracking for Generating Traffic Information. Proceedings of Transport Research Board Annual Meeting.

[47] M. Hsiao and J. Chang (2005), Segment Based Traffic Information Estimation Method Using Cellular Network Data. Proceedings of IEEE Conference on Intelligent Transportation Systems.

[48] R. Bolla and F. Davoli (2000), Road Traffic Estimation from Location Tracking Data in the Mobile Cellular Network. Proceedings of Wireless Communications and Networking Conference.

[49] C. Saraydar, S. Tekinay and W.J. Choi (2004), Efficient Vehicular Traffic Monitoring using Mobility Management in Cellular Networks. Proceedings of International Conference on Networking, Sensing \& Control.

[50] M. Linauer and D. Leihs (2003), Generating Floating Car Data by using GSM-network. $10^{\text {th }}$ ITS World Congress.

[51] W. Schneider and E. Mrakotsky (2005). Mobile Phones as a Basis for Traffic State Information. Proceedings of IEEE Conference on Intelligent Transportation Systems. 
[52] D. Myr (2003), Traffic Information Gathering via Cellular Phone Networks for Intelligent Transportation Systems. U.S. Patent 6577946.

[53] J. White, J. Quick and P. Philippou (2004), The Use of Mobile Phone Location Data for Traffic Information. Proceedings of 12th IEE International Conference on Road Transport Information \& Control.

[54] M. Alger, F. Quartier and T. Lang, (2003), Generation of Road Traffic Information from GSM Signalling Data. Proceedings of $10^{\text {th }}$ ITS World Congress.

[55] B. Rutten, P. de Wolff and M. van der Vlist (2004), GSM as the Source for Traffic Information. Proceedings of $11^{\text {th }}$ ITS World Congress.

[56] I. Feldman, A. Trinker, Y. Meltzer, A. Eshpar and A. Lotem (2003), Method and System for Modeling and processing Vehicular Traffic Data and Information and Applying Therefor. U.S. Patent 6587781.

[57] J. Kaplan, and O. Avni (2005), Method for Monitoring Cellular Communication and System therefore. U.S. Patent 6947835.

[58] C.W. Smith, C. Wilkinson, K. Carlson, M.P. Wright and R. Sangal (2005), System and Method for Providing Traffic Information using Operational Data of a Wireless Network. U.S. Patent 6842620.

[59] L. Alexander , S. Jiang , M. Murga , M.C. González (2015), Origindestination Trips by Purpose and Time of Day Inferred From Mobile Phone Data. Transportation Research Part C, pp. 240-250.

[60] P. Wang , T. Hunter , A.M. Bayen , K. Schechtner , M.C. González (2012), Understanding Road Usage Patterns in Urban Areas, Scientific reports 2:1001.

[61] N. Breyer, C. Rydergren and D. Gundlegård (2017), Cellpath Routing and Route Traffic Flow Estimation Based on Cellular Network Data. The Journal of Urban Technology, pp. 1-20.

[62] S. Mangold and S. Kyriazakos (1999), Applying Pattern Recognition Techniques based on Hidden Markov Models for Vehicular Positioning Location in Cellular Networks. Proceedings of Vehicular Technology Conference.

[63] M. Ibrahim and M. Youssef (2011), A Hidden Markov Model for Localization using Low-End GSM cell phones. Proceedings of ICC.

[64] M. Hellebrandt and R. Mathar (1999), Location Tracking of Mobiles in Cellular Radio Networks. IEEE Transactions on Vehicular Technology, Vol. 48, No. 5, pp. 1558-1562

[65] R. Schollmeyer and T. Wiltschko (2007), Classification of Public Transport Vehicles using Cellular Mobile Radio Data. Proceedings of ITS Europe. 
[66] P. Wideberg, N. Caceres and F.G. Benitez (2007), Deriving OriginDestination Data from a Mobile Phone Network. IET Intelligent Transport Systems, Vol. 1, Issue 1. pp. 15-26.

[67] S. Bekhor, M. Hirsh, S. Nimre and I. Feldman (2008), Identifying Spatial and Temporal Congestion Characteristics using Passive Mobile Phone Data. Proceedings of Transport Research Board Annual Meeting..

[68] L.P. Alexander, S. Jiang, M. Murga, M.C. González (2015), Validation of origin-destination Trips by Purpose and Time of Day Inferred from Mobile Phone Data. Transportation Research Part C.

[69] J.L. Ygnace, C. Drane (2001), Cellular Telecommunication and Transportation Convergence. Proceedings of IEEE Intelligent Transportation Systems Conference.

[70] S. Modarres Razavi, D. Yuan, "Performance Improvement of LTE Tracking Area Design: A Re-optimization Approach", Proceedings of MobiWac '08, pp. 77-84, 2008.

[71] G. Evensen (2009), Data assimilation: the ensemble Kalman filter. Springer Science \& Business Media.

[72] F. Gustafsson (2010), Statistical Sensor Fusion. Studentlitteratur, Lund.

[73] M. Lighthill and G. Whitham (1955), On kinematic waves. II. A Theory of Traffic Flow on Long Crowded Roads. Proceedings of the Royal Society of London. Series A, Mathematical and Physical Sciences 229 (1178), 317-345.

[74] C.F. Daganzo (1994), The Cell Transmission Model: A Dynamic Representation of Highway Traffic Consistent with the Hydrodynamic Theory. Transportation Research Part B 28(4), 269 - 287.

[75] R. Kalman (1960), A New Approach to Linear Filtering and Prediction Problems. Journal of Basic Engineering 82(1), 35-45.

[76] R. Kalman, R. Bucy (1961), New Results in Linear Filtering and Prediction Theory. Journal of Basic Engineering 83(1), 95-108.

[77] H. van Lint and T. Djukic (2012), Applications of Kalman Filtering in Traffic Management and Control. Tutorials in Operations Research: New Directions in Informatics, Optimization, Logistics, and Production, pp. 59-91. INFORMS.

[78] C. Antoniou, M. Ben-Akiva, H.N. Koutsopoulos (2010), Kalman Filter Applications for Traffic Management. Kalman Filter, INTECH.

[79] L. Smith, S. F. Schmidt and L. A. McGee (1962), Application of Statistical Filtering to the Optimal Estimation of Position and Velocity On-board a Circumlunar Vehicle. Technical report TR R-135, NASA. 
[80] F. Gustafsson, F. Gunnarsson, N. Bergman, U. Forssell, J. Jansson, R. Karlsson and P-J. Nordlund (2002), Particle Filters for Positioning, Navigation and tracking. IEEE Transactions on Signal Processing vol. 50 no. 2 pp. 425-437. 


\section{Paper I}

\section{The Smartphone as Enabler for Road Traffic Information Based on Cellular Network Sig- nalling}

Published in Proceedings of 16th International IEEE Conference on Intelligent Transportation Systems (ITSC), 6-9 October 2013, The Hague, Netherlands, IEEE, 2013 


\section{Paper II}

\section{Handover Location Accuracy for Travel Time Estimation in GSM and UMTS}

Published in IET Intelligent Transport Systems, Vol. 3, Issue 1, pp. 87-94 


\section{Paper III}

\section{Route Classification in Travel Time Estima- tion Based on Cellular Network Signaling}

Published in in Proceedings of 12th International IEEE Conference on Intelligent

Transport Systems (ITSC), St. Louis, October 3-7 2009, pp. 474-479, IEEE, 2009 


\section{Paper IV}

Integrated Tracking and Route Classification for Travel Time Estimation Based on Cellular Network Signalling Data

Submitted to Transportation Research Part C - Emerging Technologies 


\section{Paper V}

\section{Travel Time and Point Speed Fusion based on a Macroscopic Traffic Model and Non- linear Filtering}

Published in Proceedings of 18th International IEEE Conference on Intelligent Transportation Systems (ITSC), 15-18 September 2015, Las Palmas, Spain, IEEE, 2015 


\section{Paper VI}

\section{Travel Demand Estimation and Network Assignment Based on Cellular Network Data}

Published in Computer Communications, vol. 95, pp. 29-42, 2016 


\section{Papers}

The papers associated with this thesis have been removed for copyright reasons. For more details about these see:

http://urn.kb.se/resolve?urn=urn:nbn:se:liu:diva-152237 